\title{
Homoisoflavonoids are potent glucose transporter 2 (GLUT2) inhibitors - a potential mechanism for the glucose-lowering properties of Polygonatum odoratum
}

Huijun Wang ${ }^{\dagger, \ddagger}$, , Mark I. Fowler $₫$, David J. Messenger $₫$, Leon A. Terry ${ }^{\S}$, Xuelan Gu $\|$, Luxian Zhou ॥, Ruimin Liu ${ }^{\dagger}$, Juan $\mathrm{Su}^{\dagger}$, Songshan Shi ${ }^{\dagger}$, José Juan Ordaz-Ortiz ${ }^{\mathbf{o}}$, Guoping Lian ${ }^{\ddagger}$, Mark J. Berry *, Shunchun Wang *,†

$\dagger$ The MOE Key Laboratory for Standardization of Chinese Medicines and the SATCM Key Laboratory for New Resources and Quality Evaluation of Chinese Medicines, Institute of Chinese Materia Medica, Shanghai University of Traditional Chinese Medicine, 1200 Cailun Road, Shanghai 201203, P. R. China;

* Unilever R\&D Colworth, Colworth Science Park, Sharnbrook, Bedford MK44 1LQ, U.K.;

$\S \quad$ Plant Science Laboratory, Cranfield University, MK43 0AL, U.K.;

|| Unilever R\&D Shanghai, 5/F, 66 Lin Xin Road, Shanghai 200335, P. R. China;

$\nabla$ Central Research Institute, Shanghai Pharmaceuticals Holding Co., Ltd., Building 4, 898 Halei Road, Shanghai 201203, P. R. China;

O National Laboratory of Genomics for Biodiversity, CINVESTAV IPN, 36824 Irapuato, Guanajuato, Mexico.

\section{CORRESPONDING AUTHORS}

* Mark J. Berry, Unilever R\&D Colworth, Colworth Science Park, Sharnbrook, Bedford MK44 1LQ, U.K. Tel.: +44 1234222180; E-Mail: Mark.Berry@unilever.com ; ORCID: 0000-0002-6211-6151

* Shunchun Wang, Institute of Chinese Materia Medica, Shanghai University of Traditional Chinese Medicine, 1200 Cailun Road, Shanghai 201203, P. R. China; Tel.: +86-21-5132-2511; Fax: +86-215132-2519; E-Mail: shunchunwang@126.com ; ORCID: 0000-0003-0384-1350 


\section{ABSTRACT}

Foods of high carbohydrate content such as sucrose or starch increase postprandial blood glucose concentrations. The glucose absorption system in the intestine comprises two components: sodiumdependent glucose transporter-1 (SGLT1) and glucose transporter 2 (GLUT2). Here five sappanin-type (SAP) homoisoflavonoids were identified as novel potent GLUT2 inhibitors, with three of them isolated from the fibrous roots of Polygonatum odoratum (Mill.) Druce. SAP homoisolflavonoids had a stronger inhibitory effect on $25 \mathrm{mM}$ glucose transport $(41.6 \pm 2.5 \%, 50.5 \pm 7.6 \%, 47.5 \pm 1.9 \%$, $42.6 \pm 2.4 \%$, and $45.7 \pm 4.1 \%$ for EA-1, EA-2, EA-3, MOA, and MOB) than flavonoids $(19.3 \pm 2.2 \%$, $11.5 \pm 3.7 \%, 16.4 \pm 2.4 \%, 5.3 \pm 1.0 \%, 3.7 \pm 2.2 \%$, and $18.1 \pm 2.4 \%$ for apigenin, luteolin, quercetin, naringenin, hesperetin, and genistein) and phloretin $(28.1 \pm 1.6 \%)$ at $15 \mu \mathrm{M}$. SAP homoisoflavonoids and SGLT1 inhibitors were found to synergistically inhibit the uptake of glucose using an in vitro model comprising Caco-2 cells. This observed new mechanism of the glucose-lowering action of $P$. odoratum suggests that SAP homoisoflavonoids and their combination with flavonoid monoglucosides show promise as naturally functional ingredients for inclusion in foods and drinks designed to control post-prandial glucose levels.

KEYWORDS: Polygonatum odoratum, homoisoflavonoids, GLUT2 inhibitors, synergy, glucose control 


\section{- INTRODUCTION}

As a very common chronic disease, diabetes is becoming one of the greatest global health burdens along with cancer, cardiovascular and cerebrovascular diseases because of its high prevalence, morbidity and mortality ${ }^{1}$. The prevalence of diabetes for all adults worldwide was estimated to be 415 million in 2015 and this number is expected to increase to $c a .642$ million by $2040^{2-42-4}$. Diabetes is characterized by hyperglycemia resulting from a defect in insulin secretion, insulin action, or both ${ }^{5}$. Consumption of foods high in available carbohydrate such as sucrose or starch increases postprandial blood glucose concentrations ${ }^{6}$. It has been reported that an elevated postprandial glucose level is associated with the development of diabetes. Node et al..$^{2}$ reported high post-prandial plasma glucose “spikes" are associated with an increased risk of developing type 2 diabetes. Controlling the post-meal glucose level is known to be important in both diabetic patients as well as normal healthy subjects ${ }^{7,8}$. Unregulated glycemic excursions are undesirable, and any reduction or "blunting" of the post-prandial glucose concentration in blood is potentially beneficial.

The glucose absorption system in the intestine comprises two components. One is a well-established component mediated by the apically located, sodium-dependent glucose transporter-1 (SGLT1), a high-affinity, low-capacity, active transport protein. The other component is glucose transporter 2 (GLUT2), a low-affinity, high-capacity, facilitated transport protein ${ }^{9,}{ }^{10}$. Kellett et al. ${ }^{11}$ described the potential interplay of these transporters during the consumption of a carbohydrate rich meal. We have illustrated this interplay schematically in Figure S1. Before the meal, the concentration of free glucose in the lumen of the intestine is low $(<5 \mathrm{mM})$ and the apically expressed SGLT1 transporter actively transports any available glucose into the enterocyte. GLUT2 transporters are also active on the basolateral membrane of the enterocyte, transporting glucose from the blood into the cell to maintain 
cellular metabolism if required. During a meal, the local concentration of glucose begins to increase $(5-10 \mathrm{mM})$ and is transported from the intestinal lumen by SGLT1 and subsequently into the systemic circulation via GLUT2. As a consequence of this initial glucose transport across the enterocyte, intracellular stores of GLUT2 are mobilized and targeted to the apical membrane. Shortly after the meal, very high local concentrations of glucose occur $(25-100 \mathrm{mM})$ as the carbohydrate content of the meal is broken down into monosaccharides by alpha-glycosidase enzymes located on the apical enterocyte membrane. At these high levels of glucose, the high affinity, low capacity transporter SGLT1 becomes saturated and the majority of glucose transport across the enterocyte is due to the low affinity, high capacity GLUT2 transporters now present in the apical membrane ${ }^{12}$. Flavonoids, (a class of polyphenols) that are widely distributed in food, especially fruits and vegetables, have been reported to have GLUT2 inhibitory effects, including quercetin, isoquercitrin, myricetin, apigenin, luteolin, hesperetin, and hesperidin, however, most of their glycosides are SGLT1 inhibitors ${ }^{13,14}$.

Polygonatum odoratum (Mill.) Druce, a famous Yin-nourishing herb in traditional Chinese medicine and an edible food, which grows wildly and is also cultivated in most areas of China, has been used for hundreds of years to treat many diseases including diabetes ${ }^{15}$. Previous bioactivity investigation of $P$. odoratum showed that the extracts or ingredients from its fibrous root had glucoselowering effects with the mechanisms of action involving increasing insulin sensitivity ${ }^{16}$, increasing insulin-stimulated glucose uptake ${ }^{15}$, inhibiting advanced protein glycation ${ }^{17}$, or inhibiting alphaamylase/alpha-glycosidase enzymes ${ }^{18}$. Wang et al. ${ }^{19}$ reported that the ethanol extract of $P$. odoratum showed potent intestinal glucose transport inhibitory effect. In this study, we investigated the chemical constituents of ethanol extracts of $P$. odoratum and the potential glucose transport inhibitors. Bioassaydirected fractionation led to the isolation of a series of homoisoflavonoids with novel potent GLUT2 
inhibitory activity. In addition, these homoisoflavonoids demonstrated synergistic inhibition of glucose transport when combined with previously identified SGLT1-specific antagonists ${ }^{20}$.

\section{- MATERIALS AND METHODS}

Materials. The reagents of sodium pyruvate solution, D-(+)-glucose, 2-Deoxyglucose, Lucifer Yellow, and fetal bovine serum (FBS) were obtained from Sigma-Aldrich (St. Louis, MO). DMEM+Glutamax-1, Non Essential Amino Acids and dimethyl sulfoxide was purchased from Merck (Gibbstown, NJ). The Amplex Red Glucose/Glucose Oxidase Assay Kit was purchased from Invitrogen (Carlsbad, CA). For cell culture, human epithelial colorectal adenocarcinoma (Caco-2) cells were purchased from American Type Culture Collection (Manassas, VA).

Chemicals. Apigenin, luteolin, quercetin, naringenin, hesperetin, genistein, tectoridin, phloridzin, and phloretin were obtained from Sigma-Aldrich (St. Louis, MO). Luteolin-7-glucoside, myrtillin chloride, naringenin-7-O-glucoside, kaempferol-3-glucoside, and apigenin-8-C-glucoside were purchased from Extrasynthese (Genay, France). Methylophiopogonanone A (MOA) and Methylophiopogonanone B (MOB) were purchased from Shanghai PureOne, Biotechnology Co. Ltd. (Shanghai, China)

Plant material Polygonatum odoratum (Mill.) Druce, rhizoma, dried were purchased from Shanghai Kangqiao Pharmacy Co., Ltd. (authenticated by Prof. L.H. Wu at the Institute of Chinese Materia Medica, Shanghai University of Traditional Chinese Medicine, Shanghai), and deposited at the Herbarium of the Institute of Chinese Materia Medica, Shanghai University of Traditional Chinese Medicine, Shanghai. The information includes the producing area (Jiangsu), lot number (111126), and voucher specimen (yz12041211). 
Extraction and isolation. $P$. odoratum $(1.0 \mathrm{~kg})$ was extracted with an aqueous solution of $95 \%$ ethanol for $2 \mathrm{~h}$ at a solid-liquid weight ratio of 1:4. The remaining plant root was then extracted with an aqueous solution of $70 \%$ ethanol for $2 \mathrm{~h}$ at a solid-liquid weight ratio of 1:3. The two aqueousethanol extracts were then combined, concentrated and vacuum dried to yield $333.1 \mathrm{~g}$ (yield rate $33.3 \%$ ) P. odoratum aqueous ethanol extract ${ }^{19}$.

The dried extract (333.1 g) was dissolved in water and partitioned sequentially with petroleum ether, ethyl acetate and 1-butanol to obtain once dried $21.0 \mathrm{~g}$ petroleum ether extract (yield rate 6.3\%), 4.33 g ethyl acetate extract (yield rate 1.3\%), $29.3 \mathrm{~g}$ 1-butanol extract (yield rate 8.8\%) and $216.5 \mathrm{~g}$ water extract (yield rate $65.0 \%$ ).

The ethyl acetate extract was further purified using a LC3000 semi-preparative HPLC system fitted with a YMC-Pack-C18 column $(250 \mathrm{~mm} \times 10 \mathrm{~mm}, 5 \mu \mathrm{m})$. Compounds were eluted isocratically $(60 \%$ acetonitrile, $40 \%$ water with $0.18 \%$ formic acid) and the signal was monitored at $280 \mathrm{~nm}$ at a flow rate of $6 \mathrm{ml} / \mathrm{min}$. This separation method provided two mixtures (EA-A and EA-B) and three pure compounds, namely EA-1 (38.3 mg, yield rate 0.885\%), EA-2 (59.0 mg, yield rate 1.362\%), and EA$3(93.8 \mathrm{mg}$, yield rate $2.167 \%$ ) (Figure S2a).

HR-ESI-MS were obtained on a Waters Premier QTOF mass spectrometer, coupled to an UPLC that comprised of an Acquity Waters Ultra-Performance Liquid Chromatographic system equipped with a Waters UPLC column (Acquity UPLC BEH C18, $2.1 \times 50 \mathrm{~mm}, 1.7 \mu \mathrm{m}$,) and a Micromass ZQ 2000 ESI mass spectrometer. NMR spectra were obtained on a Bruker AVANCE-III instrument (600 MHz) for ${ }^{1} \mathrm{H}$ and ${ }^{13} \mathrm{C}$, with tetramethylsilane as internal standard.

\section{Glucose transport assay}


Cell culture. Caco-2 cells were cultured in Growth Medium consisting of Dulbecco's modified Eagle's medium (containing Glutamax-1, $4.5 \mathrm{~g} / \mathrm{L}$ D-glucose and $25 \mathrm{mM}$ 4-(2-hydroxyethyl)-1piperazine ethanesulphonic acid (HEPES) (Invitrogen)), 10\% FBS, 1\% non-essential amino acids (Invitrogen) and $1 \mathrm{mM}$ sodium pyruvate (Sigma)). The cells were routinely passaged at approximately 80\% confluence using TrypLE ${ }^{\mathrm{TM}}$ Express Stable Trypsin-Like Enzyme (Invitrogen) to detach the cells, and seeded at approximately 114 cells $/ \mathrm{mm}^{2}$ in fresh tissue culture flasks. Only cells between the passage numbers 45 and 49 were used for these experiments ${ }^{21}$.

The method for the formation of differentiated monolayers with good membrane integrity was based on the previous report of Yamashita et al. ${ }^{22}$ Corning® HTS Transwell ${ }^{\circledR} 96$ well permeable insert supports (Sigma) were collagen coated with $40 \mu \mathrm{L}$ of $50 \mu \mathrm{g} / \mathrm{mL}$ collagen type I (BD Biosciences) in $0.02 \mathrm{M}$ acetic acid for one hour at room temperature under sterile conditions. The inserts were washed twice in phosphate buffered saline (PBS (Invitrogen)) and the Caco-2 cells seeded into the inserts at $9.6 \times 10^{5}$ cell $/ \mathrm{mL}(75 \mu \mathrm{L}$ per insert $)$ in Growth Medium and $30 \mathrm{~mL}$ of Growth Medium added to the feeder plate below. The cells were left to attach to the collagen matrix and form monolayers over $48 \mathrm{~h}$ at $37{ }^{\circ} \mathrm{C}, 5 \% \mathrm{CO}_{2}$. Both inserts and feeder plate were washed in PBS and the cells incubated with BD Entero-STIM ${ }^{\mathrm{TM}}$ Enterocyte Differentiation Medium containing MITO+TM Serum Extender solution (both BD Biosciences), $75 \mu \mathrm{L}$ per insert and $30 \mathrm{~mL}$ in the feeder plate, for a further $48 \mathrm{~h}$ at $37{ }^{\circ} \mathrm{C}, 5 \%$ $\mathrm{CO}_{2}$.

Glucose transport inhibitor cell screening assay. Differentiated cell monolayers were washed gently in Dulbecco's Phosphate Buffered Saline containing $\mathrm{CaCl}_{2}$ and $\mathrm{MgCl}_{2}(\mathrm{PBS}(+)$ (Invitrogen)) and the inserts transferred to a new Corning® HTS Transwell®-96 well receiver plate (Sigma). The cells were incubated with fresh $\mathrm{PBS}(+)\left(75 \mu \mathrm{L}\right.$ per insert and $225 \mu \mathrm{L}$ per well) for 45 min at $37{ }^{\circ} \mathrm{C}, 5 \% \mathrm{CO}_{2}$. 
The PBS(+) was gently aspirated and replaced with $75 \mu \mathrm{L}$ per insert of either $5 \mathrm{mM}$ D-glucose (simulated fasting state) \pm test compound or $25 \mathrm{mM}$ D-glucose (simulated fed state) \pm test compound in triplicate and $225 \mu \mathrm{L}$ per well of PBS(+) quickly added to each well. The $5 \mathrm{mM}$ glucose wells and the $25 \mathrm{mM}$ glucose wells were incubated at $37{ }^{\circ} \mathrm{C}, 5 \% \mathrm{CO}_{2}$ for $15 \mathrm{~min}$ and $30 \mathrm{~min}$, respectively. The cell inserts were transferred to a new receiver plate, the supernatant gently aspirated from the cells and replaced with $100 \mu \mathrm{L}$ of a $100 \mu \mathrm{M}$ Lucifer Yellow (Sigma) solution to confirm the integrity of the monolayers. $225 \mu \mathrm{L}$ of $\mathrm{PBS}(+)$ was added to each well and incubated at $37{ }^{\circ} \mathrm{C}, 5 \% \mathrm{CO}_{2}$ for $1 \mathrm{~h}$. The cell inserts were then discarded and the permeability of the membranes to Lucifer Yellow checked by measuring the fluorescence of the samples at $485 \mathrm{~nm}$ (excitation) and $530 \mathrm{~nm}$ (emission) on a Spectramax Gemini EM fluorescence microplate reader ${ }^{22} .300 \mu \mathrm{M} \mathrm{Pz}$ and $150 \mu \mathrm{M}$ Pt were used as positive controls of simulated fasting and fed states, respectively.

Glucose assay. The amount of glucose transported across the cell monolayers was measured using a glucose oxidase assay. Briefly, $50 \mu \mathrm{L}$ of each test sample was transferred to a black sided/clear bottom 96-well plate (Greiner Bio-One) to which $100 \mu \mathrm{L}$ of reaction buffer (0.5 $\mu \mathrm{L} 10 \mathrm{mM}$ Ampliflu Red, 1 $\mu \mathrm{L} 10 \mathrm{U} / \mathrm{mL}$ Horse Radish peroxidase, $1 \mu \mathrm{L} 100 \mathrm{U} / \mathrm{mL}$ glucose oxidase and $97.5 \mu \mathrm{L}$ PBS (all Sigma)) was added. After $10 \mathrm{~min}$ incubation at room temperature, the fluorescence of the samples was measured at $530 \mathrm{~nm}$ (excitation) and $590 \mathrm{~nm}$ (emission) on a Spectramax Gemini EM fluorescence microplate reader and the glucose concentration extrapolated from a standard curve ${ }^{19,23}$.

\section{2-Deoxyglucose transport assay}

Preparation of differentiated Caco-2 cell monolayers. Caco-2 cells were cultured and routinely passaged as described in Glucose transport assay. Caco-2 cells were seeded into BioCoat HTS Fibrillar 
Collagen Multiwell Inserts (BD Biosciences) at $2.5 \times 10^{5}$ cell/ml (500 $\mu$ l per insert) in Growth Medium and $30 \mathrm{ml}$ of Growth Medium added to the feeder plate below. The cells were left to attach to the collagen matrix and form monolayers over $24 \mathrm{~h}$ at $37^{\circ} \mathrm{C}, 5 \% \mathrm{CO}_{2}$. Both inserts and feeder plate were washed in PBS and the cells incubated with BD Entero-STIM ${ }^{\mathrm{TM}}$ Enterocyte Differentiation Medium containing MITO+TM Serum Extender solution (both BD Biosciences), $500 \mu 1$ per insert and $30 \mathrm{ml}$ in feeder plate, for a further $48 \mathrm{~h}$ at $37^{\circ} \mathrm{C}, 5 \% \mathrm{CO}_{2}$.

2-Deoxyglucose transport cell model. Differentiated cell monolayers were washed gently in Dulbecco's Phosphate Buffered Saline containing $\mathrm{CaCl}_{2}$ and $\mathrm{MgCl}_{2}$ (PBS (+) (Invitrogen)) and the inserts transferred to a new standard tissue culture 24-well plate. The cells were incubated with fresh PBS (+) $(500 \mu \mathrm{L}$ per insert and $1 \mathrm{~mL}$ per well $)$ for $45 \mathrm{~min}$ at $37^{\circ} \mathrm{C}, 5 \% \mathrm{CO}_{2}$. The $\mathrm{PBS}(+)$ was gently aspirated and replaced with $500 \mu \mathrm{L}$ per insert of $25 \mathrm{mM}$ 2-Deoxyglucose \pm test compound in triplicate and $1 \mathrm{~mL}$ per well of $\mathrm{PBS}(+)$ quickly added to each well. The wells were incubated at $37{ }^{\circ} \mathrm{C}, 5 \% \mathrm{CO}_{2}$ for $30 \mathrm{~min}$. The cell inserts were transferred to a new receiver plate, the supernatant gently aspirated from the cells and replaced with $500 \mu \mathrm{L}$ of a $100 \mu \mathrm{M}$ Lucifer Yellow (Sigma) solution to confirm the integrity of the monolayers. The details of Lucifer Yellow assay was described in the glucose transport assay section.

2-Deoxyglucose assay. A $200 \mu \mathrm{L}$ sample from each well was added to $1 \mathrm{~mL}$ of $0.5 \mathrm{M}$ $\mathrm{NaBH}_{4} /$ dimethyl sulfoxide (DMSO). Acetic acid $(100 \mu \mathrm{L})$ was added dropwise to reduce the abundance of $\mathrm{NaBH}_{4}$ after the reduction reaction $\left(90 \mathrm{~min}\right.$ at $\left.40{ }^{\circ} \mathrm{C}\right) .100 \mu \mathrm{L}$ of this solution was acetylated $\left(10 \mathrm{~min}\right.$ at $\left.40{ }^{\circ} \mathrm{C}\right)$ after adding $200 \mu \mathrm{L}$ of 1 -methylimidazole and $1 \mathrm{~mL}$ of acetic anhydride. Subsequently, $2 \mathrm{~mL}$ of water was added to the extracts for $10 \mathrm{~min}$ at $40{ }^{\circ} \mathrm{C}$, and the mixtures were extracted with $2 \mathrm{~mL}$ of chloroform. The samples were centrifuged $(4000 \times \mathrm{g}$ for $10 \mathrm{~min})$, and the 
aqueous layer was discarded. The samples were washed with $2 \mathrm{~mL}$ of water. The samples were dried over $1 \mathrm{~g}$ sodium sulfate and taken for GC-MS. $25 \mathrm{mM}$ arabinose $(2 \mu \mathrm{L})$ was used as an internal standard in each $200 \mu \mathrm{L}$ starting sample ${ }^{24}$.

GC-MS was performed using an Agilent 6890 gas chromatograph (USA) coupled with a mass spectrometer (Agilent 5975, USA). A DB-5 capillary column $(30 \mathrm{~m} \times 0.25 \mathrm{~mm} \times 0.25 \mu \mathrm{m}$, Agilent) was used with an inlet temperature of $275^{\circ} \mathrm{C}$. Column temperature was increased from an initial $140{ }^{\circ} \mathrm{C}$ to $185^{\circ} \mathrm{C}\left(5^{\circ} \mathrm{C} / \mathrm{min}\right)$. It was then increased from $185^{\circ} \mathrm{C}$ to $190{ }^{\circ} \mathrm{C}\left(1{ }^{\circ} \mathrm{C} / \mathrm{min}\right)$, and $190{ }^{\circ} \mathrm{C}$ to $250{ }^{\circ} \mathrm{C}\left(10^{\circ} \mathrm{C} / \mathrm{min}\right)$. Helium was used as a carrier gas at a flow rate of $0.9 \mathrm{~mL} / \mathrm{min}$ with split ratio $10: 1$ and $1 \mu \mathrm{L}$ sample aliquots were injected. The mass spectrometer was operated in electron impact and full-scan monitoring modes (m/z 25-300). Source temperature, electron energy, and solvent delay were set at $280{ }^{\circ} \mathrm{C}, 70 \mathrm{eV}$ and 5 min respectively.

\section{Synergy between SGLT1 inhibitors and homoisoflavonoids}

Preparation of differentiated Caco-2 cell monolayers and glucose transport cell model. Caco-2 cell culture and the method for the formation of differentiated monolayers were the same as the 2Deoxyglucose transport assay. Differentiated cell monolayers were washed gently in $\mathrm{PBS}(+)$ and the inserts transferred to a new standard tissue culture 24-well plate. The cells were incubated with fresh $\operatorname{PBS}(+)\left(500 \mu \mathrm{l}\right.$ per insert and $1 \mathrm{ml}$ per well) for $30 \mathrm{~min}$ at $37^{\circ} \mathrm{C}$ and $5 \% \mathrm{CO}_{2}$. The $\mathrm{PBS}(+)$ was gently aspirated and replaced with $250 \mu \mathrm{l}$ per insert of $5 \mathrm{mM}$ D-glucose \pm test compound and $1 \mathrm{ml}$ of PBS(+) quickly added to each well below before the cells were replaced in the incubator at $37^{\circ} \mathrm{C}$ and $5 \% \mathrm{CO}_{2}$. After $15 \mathrm{~min}$, the cell inserts were transferred to a new 24-well plate, and a further $250 \mu \mathrm{l}$ of $45 \mathrm{mM}$ D-glucose \pm test compound was added to each insert (resulting in a final concentration of glucose of 
$25 \mathrm{mM}$ ) and again $1 \mathrm{ml}$ of PBS(+) added to the wells. After a further $15 \mathrm{~min}$ the inserts were transferred to a new 24-well plate and this time only fresh PBS(+) was added to the wells below. This step was repeated after another $15 \mathrm{~min}$. The integrity of the monolayers was confirmed using Lucifer Yellow as described previously.

Glucose assay. After the last incubation, all of the retained PBS(+) from each step (i.e. at 15, 30, 45 and $60 \mathrm{~min}$ ) was assayed for glucose levels as described in Example 1, and the total cumulative glucose transport calculated. The localized changes in luminal glucose concentrations described and illustrated in example 1 are mimicked in-vitro through an initial short incubation of differentiated Caco-2 cells with a low level of D-glucose ( $5 \mathrm{mM}$ for $15 \mathrm{~min}$ ) immediately followed by a sustained incubation with a high level of D-glucose (final concentration of $25 \mathrm{mM}$ for $45 \mathrm{~min}$ ).

Statistical analysis. All data are expressed as mean \pm standard error of the mean. Statistical analysis was performed with one-way ANOVA using GraphPad Prism 5.01 (GraphPad Software, San Diego, CA, USA). Treatment differences were subjected to Tukey's multiple comparison tests. Differences with $\mathrm{p}<0.05$ were considered statistically significant.

\section{- RESULTS AND DISCUSSION}

Isolation and structure elucidation of homoisoflavonoids from $\boldsymbol{P}$. odoratum. To find a novel and potent glucose transport inhibitor and further target for functional ingredient development, bioassaydirected fractionation of the ethyl acetate fraction of the aqueous ethanol extract of a dried root part of P. odoratum, by semi-preparative HPLC system as detailed in the experimental section was performed. This led to the isolation of two mixtures (EA-A and EA-B) and three pure compounds, namely EA-1, EA-2 and EA-3 (Figure S2a). EA-1, EA-2 and EA-3, with stronger glucose transport inhibitory effect 
than EA-A and EA-B (Figure S2b), were identified by comparing their spectroscopic data $\left({ }^{1} \mathrm{H},{ }^{13} \mathrm{C}\right.$ NMR, MS) (Figure S3-S9) with those reported ${ }^{25,26}$. They are 5,7-dihydroxy-3-(4'-hydroxybenzyl)-6methylchroman-4-one (EA-1), 5,7-dihydroxy-3-(4'-hydroxybenzyl)-6-methyl-8-methoxychroman-4one (EA-2), and 5,7-dihydroxy-3-(4'-hydroxybenzyl)-6, 8-dimethylchroman-4-one respectively. Zhang et al. ${ }^{15}$ reported that the ethyl acetate soluble fraction of a $90 \%$ methanol extract of the fibrous roots of $P$. odoratum affected an insulin-stimulated glucose uptake in differentiated 3T3L1 adipocytes. Bioassay-guided fractionation yielded nine homoisoflavonoids, together with an isoflavone glycoside and a flavanone glycoside, including EA-1, EA-2, EA-3 and tectoridin, which indicated that homoisoflavonoids may be potential insulin sensitizers. However, we are not aware of any reports about homoisoflavonoids having an effect on glucose transport. Previous phytochemical investigations on P. odoratum resulted in the isolation of nineteen homoisoflavonoids (Figure 1) $)^{27,28}$. However, in our study, only three homoisoflavonoids (9: EA-1, 10: EA-2, 11: EA-3) were obtained by the method of bioassay-directed fractionation. This specific assay may thus have not allowed the isolation of other homoisoflavonoids of either lower concentration or activity. To expand the sample size for our study of the bioactivity, mechanism and synergy, another two homoisoflavonoids, namely methylophiopogonanone A (MOA) and methylophiopogonanone B (MOB), were purchased (Shanghai PureOne, Biotechnology Co. Ltd); the other homoisoflavonoids are not commercial available. All five homoisoflavonoids had similar structure (Figure 2).

P. odoratum extracts \& homoisoflavonoids inhibit glucose transport. Table 1 shows that a crude aqueous ethanol extract of $P$. odoratum can significantly inhibit glucose transport across a differentiated monolayer of Caco-2 cells at both low (simulated fasted state) and high (simulated fed state) glucose concentrations. Further sequential partition demonstrated a similar inhibition activity 
with both the petroleum ether (PE) and ethyl acetate (EA) fractions. However, the 1-butanol fraction only exhibited significant glucose transport inhibition activity at the lowest glucose concentration and no inhibitory activity was detected in the water fraction.

The EA fraction was chosen for further purification based on its high glucose transport inhibition activity, yielding five sub-fractions, two of which were mixtures (EA-A and EA-B) and the rest which were mainly single compounds (EA-1, EA-2 \& EA-3). While EA-A only demonstrated significant glucose transport inhibition at low glucose levels, the other sub-fractions all inhibited glucose transport at both glucose concentrations. In addition, the commercially available homoisoflavonoids, methylophiopogonanone A (MOA) and methylophiopogonanone B (MOB), also significantly inhibited glucose transport at both low and high glucose concentrations (Table 1).

Homoisoflavonoids are potent GLUT2 inhibitors. Berry et al. ${ }^{20}$ suggested that a compound with $>20 \%$ inhibition of glucose transport at both low $(5 \mathrm{mM})$ and high $(25 \mathrm{mM})$ glucose concentrations was indicative of a GLUT2-specific inhibitor. Since all five pure homoisoflavonoids (EA-1, EA-2, EA-3, MOA and MOB) met this specification (Table 1), their GLUT2 specificity was confirmed using 2-deoxyglucose, which is only transported by GLUT2 and not by SGLT1 ${ }^{13,29}$. The data showed that all five homoisoflavonoids, at $15 \mu \mathrm{M}$ inhibited 2-deoxyglucose transport (25 mM) with the inhibition rate corresponding to the glucose transport inhibition rate (Figure $3 \mathrm{~A}$ ). In addition, the well characterized GLUT2 specific inhibitor, phloretin ${ }^{11}$, demonstrated a similar pattern of inhibition to the homoisoflavonoids suggesting that they are indeed GLUT2 inhibitors.

In our study, EA-1, EA-2, and EA-3 have good solubility in PBS(+) glucose solution, with $\mathrm{IC}_{50}$ values of $47.43 \mu \mathrm{M}, 53.47 \mu \mathrm{M}$, and $21.14 \mu \mathrm{M}$ at $25 \mathrm{mM}$ glucose, respectively (Figure $3 \mathrm{~B}$ ). The low 
$\mathrm{IC}_{50}$ values of EA-1, EA-2 and EA-3 demonstrates the potent glucose transport inhibitory activity of these homoisoflavonoids. The $\mathrm{IC}_{50}$ values of $\mathrm{MOA}$ and $\mathrm{MOB}$ could not be obtained due to solubility issues at higher concentrations. However, interestingly all five homoisoflavonoids have good solubility at $15 \mu \mathrm{M}$, therefore the concentration of $15 \mu \mathrm{M}$ was selected as the test concentration for the following studies. Surprisingly, at this concentration the five homoisoflavonoids (EA-1, EA-2, EA-3, MOA and MOB) exhibited significantly enhanced glucose transport inhibitory activities than the GLUT2 inhibitor phloretin at high glucose concentrations (Figure 4). In addition, the homoisoflavonoids showed stronger inhibitory effects on $25 \mathrm{mM}$ glucose transport than flavonoid aglycones (apigenin, luteolin, quercetin, naringenin, hesperetin, and genistein) (Figure 4) which have been widely identified as effective GLUT2 inhibitors ${ }^{13,14}$. Indeed, the $\mathrm{IC}_{50}$ on $25 \mathrm{mM}$ glucose transport of EA-1, EA-2 and EA-3 were lower than apigenin $(259.5 \mu \mathrm{M})$, luteolin $(62.4 \mu \mathrm{M})$, naringenin $(295.1 \mu \mathrm{M})$, hesperetin $(162.7 \mu \mathrm{M})$, and genistein $(157.8 \mu \mathrm{M})$ and similar to quercetin $(41.6 \mu \mathrm{M})$ (Table S1).

Synergy between homoisoflavonoids and flavonoid monoglucosides. Berry et al. ${ }^{20}$ demonstrated the synergistic inhibition of glucose transport across a differentiated Caco-2 monolayer by combining both SGLT1 and GLUT2 inhibitors in a cell model designed to mimic the local changes in glucose concentration during the digestion of a carbohydrate rich meal. Figure 5 plots the total cumulative glucose transport across a differentiated Caco-2 monolayers in the presence or absence of a SGLT1 inhibitor for the first $15 \mathrm{~min}$ in $5 \mathrm{mM} \mathrm{D}$-glucose and subsequently in the presence or absence of a GLUT2 inhibitor in $25 \mathrm{mM}$ D-glucose for the remaining $45 \mathrm{~min}$. To validate this cell system, Pz and Pt were used as the widely accepted specific inhibitors of SGLT1 and GLUT2 respectively (Figure 5A). Pz shows a reduction in total Cumulative Glucose Transport (tCGT) when added from the beginning of the cell system (Pz NC-horizontal striped bar), demonstrating the inhibition of SGLT1 
which is the dominant active transporter at low glucose levels. However Pz exhibits no inhibition on tCGT when added later with the high concentration of D-glucose (NC Pz -dotted bar) since the SGLT1 transporters are now saturated and glucose transport is now dependent on the high capacity GLUT2 transporters. Pt demonstrates a significant reduction in tCGT when added with the high concentration of D-glucose as expected (NC Pt -diagonal striped bars). However a combination of $300 \mu \mathrm{M} \mathrm{Pz}$ at low glucose concentrations, followed by $125 \mu \mathrm{M}$ Pt at the high glucose concentration appears to significantly and synergistically inhibit the tCGT. This synergy exploits the requirement of an initial transport of glucose into the enterocyte by SGLT1 before the high-capacity GLUT2 can be targeted to the apical membrane. Used in combination, both SGLT1 and GLUT2 inhibitors can synergistically inhibit the localized uptake of glucose from the intestinal lumen and hence potentially reduce the high 'spikes' of postprandial blood glucose associated with the potential risk of developing type 2 diabetes.

Berry et al. ${ }^{20}$ disclosed examples of SGLT1 inhibitors, all being flavonoid monoglucosides, such as luteolin-7-glucoside, apigenin-7-glucoside, apigenin-8-c-glucoside, kaempferol-3-glucoside, kaempferol-7-glucoside, quercetin-3-glucoside, quercetin-4-glucoside, naringenin-7-glucoside, eriodictiol-7-glucoside, daidzein-8-C-glucoside, daidzein-7-glucoside, cyanidin-3-glucoside, malvidin-3-O-glucoside, delphinidin-3-glucoside (myrtillin chloride) and pelargonidin-3-glucoside. Indeed, the presence of an additional glucose moiety on the chemical structure removes this inhibitory action as demonstrated by quercetin-3,4'-diglucoside. The specificity for a glucoside is confirmed by the absence of SGLT1 inhibitory activity by other flavonoid glycosides tested, including cyanidin-3rutinoside and malvidin-3-O-galactoside. In addition, the lack of SGLT1 inhibitory activity shown by the hydroquinone monoglucoside, arbutin, reinforces the importance of a flavonoid and dihydrochalcone structures in the glucoside molecule. Tectoridin, a flavonoid monoglucoside present 
in $P$. odoratum ${ }^{15}$, might be a SGLT1 inhibitors as well, with a glucose transport inhibition rate at $5 \mathrm{mM}$ glucose of $29.41 \pm 0.62 \%$ and $4.92 \pm 2.08 \%$ at $25 \mathrm{mM}$ glucose with $300 \mu \mathrm{M}$ tectoridin.

Figure 5 summarises the results using the above-mentioned Caco-2 assay with combinations of selected homoisoflavonoids, as potent GLUT2 inhibitors and SGLT1 inhibitors (a variety of flavonoid monoglucosides) and clearly shows that in combination, both SGLT1 inhibitors and homoisoflavonoids can synergistically inhibit glucose transport. For example, the specific SGLT1 inhibitor tectoridin (isoflavone monoglucoside, $300 \mu \mathrm{M}$ ) was combined with the specific GLUT2 inhibitor EA-1 (homoisoflavonoids, $10 \mu \mathrm{M}$ ) to demonstrate the synergistic inhibition of glucose transport across a differentiated Caco-2 cell monolayer (Figure 5B). Combining luteolin-7-glucoside (flavone monoglucoside, $300 \mu \mathrm{M}$ ) \& EA-1 (homoisoflavonoids, $10 \mu \mathrm{M}$ ) (Figure 5C), or myrtillin chloride (anthocyanin, $300 \mu \mathrm{M}$ ) \& MOB (homoisoflavonoids, $5 \mu \mathrm{M}$ ) (Figure 5D), or naringenin-7-Oglucoside (flavanone monoglucoside, $300 \mu \mathrm{M}$ ) \& MOB (homoisoflavonoids (Figure 5E), $5 \mu \mathrm{M}$ ), or kaempferol-3-glucoside (flavonol monoglucoside, $150 \mu \mathrm{M}$ ) \& EA-2 (homoisoflavonoids, $10 \mu \mathrm{M}$ ) (Figure 5F), tectoridin (isoflavone monoglucoside, $300 \mu \mathrm{M}$ ) \& MOA (homoisoflavonoids, $5 \mu \mathrm{M}$ ) (Figure 5G), or apigenin-8-C-glucoside (flavone monoglucoside, $300 \mu \mathrm{M}$ ) $\quad$ \& $\quad$ EA-3 (homoisoflavonoids, $2.5 \mu \mathrm{M}$ ) (Figure 5H), demonstrated the synergistic inhibition of glucose transport across a differentiated Caco- 2 cell monolayer.

Discussion. Diabetes is characterized by hyperglycemia, which can cause diabetic complications including cardiovascular disease, nephropathy, retinopathy, and neuropathy ${ }^{30}$. Disturbance of glucose homeostasis is a major factor in the development of hyperglycemia. In type 2 diabetes, pancreatic beta cells are damaged or become dysfunctional because of the persistently high glucose or lipid levels, inflammatory mediators released from the adipose tissue and endoplasmic reticulum, or oxidative 
stress $^{31,32}$. Thus controlling the post-meal glucose level may be a strategic approach for the prevention and treatment of diabetes ${ }^{7,8}$. In our study, we demonstrated for the first time that homoisoflavonoids have an inhibitory effect on glucose transport in intestinal cells. Fractions EA-1, EA-2, EA-3 were isolated from the fibrous roots of $P$. odoratum; MOA and MOB were purchased from commercial suppliers who had isolated them from the root tubers of Ophiopogon japonicus (Asparagaceae family).

Homoisoflavonoids, a subclass of flavonoids, are rarely found in nature: they have only been identified in six plant families so far (Asparagaceae, Fabaceae, Polygonaceae, Portulacaceae, Orchidaceae, and Gentianaceae $)^{27}$. The majority of homoisoflavonoids have been reported from the families of Asparagaceae ( $P$. odoratum belongs to Asparagaceae family) and Fabaceae ${ }^{27}$. The homoisoflavonoids are classified into five groups based on their structures: sappanin-type (I), scillascillin-type (II), brazilin-type (III), caesalpin-type (IV), and protosappanin-type (V). EA-1, EA2, EA-3, MOA, and MOB were classed as sappanin-type homoisoflavonoids (SAP homoisoflavonoids) bearing a 3-benzyl chromane skeleton, in which the benzopyran and aromatic rings are connected via one carbon, however, the benzopyran and aromatic rings are connected directly for the structure of flavonoids. As of 2014, 191 SAP homoisoflavonoids have been isolated and structurally elucidated ${ }^{27}$. SAP homoisoflavonoids have shown significant activities in the regulation of insulin-stimulated glucose uptake in differentiated 3T3-L1 adipocytes ${ }^{15}$, AMPK and acetyl-CoA carboxylase in IAR-20 cells $^{33}$, and advanced glycation end product formation ${ }^{34}$. Moreover, the results in the present study indicated that SAP homoisoflavonoids are potent GLUT2 inhibitors, with significantly higher glucose transport inhibitory activities than phloretin at high glucose concentrations. In addition, the SAP homoisoflavonoids showed stronger inhibitory effects on $25 \mathrm{mM}$ glucose transport than flavonoid aglycones (apigenin, luteolin, quercetin, naringenin, hesperetin, and genistein). 
P. odoratum is native to Europe, Caucasus, Siberia, Russian Far East, China, Mongolia, Korea and $\operatorname{Japan}^{28}$. In China, it is cultivated in most areas, its rhizomes have been widely used as an ingredient/supplement in food (e.g. functional/healthy food, flavours and tea preparation), and a wellknown traditional Chinese medicine for removing dryness, promoting secretion of fluid and quenching thirst $^{35}$. In our study, three SAP homoisoflavonoids (EA-1, EA-2, EA-3) were isolated from the fibrous roots of $P$. odoratum; with potent GLUT2 inhibitory effects. Additionally, sixteen other SAP homoisoflavonoids have been isolated from P. odoratum (Figure 1) ${ }^{27}, 28$. Interestingly, flavonoid monoglucosides (SGLT1 inhibitors) were also isolated from P. odoratum (e.g. tectoridin, hesperidin and 4'-demethylleucomin 7-O- $\beta$-D-glucopyranoside ${ }^{15}$. Since both SAP homoisoflavonoids and flavonoid glycosides are present in P. odoratum, they may show synergetic effects on glucose-lowering in diabetic patients. These results suggest a new mechanism for the anti-diabetic action of $P$. odoratum and suggest that consumption of $P$. odoratum (containing both SAP homoisoflavonoids and flavonoid glycosides) may be beneficial for the reduction or "blunting" of post-prandial glucose concentration in blood. However, the very low abundance of these flavonoid monoglucosides in P. odoratum may prevent the efficient synergy with SAP homoisoflavonoids suggesting that a combination of $P$. odoratum with a plentiful source of flavonoid monoglucosides would be a promising new nutraceutical agent or functional food ingredient for controlling post-prandial blood glucose.

\section{- ASSOCIATED CONTENT}

\section{Supporting information}

Glucose transport inhibitory effect and $\mathrm{IC}_{50}$ of homoisoflavonoids and flavonoids; A model of the glucose concentration timeline during a meal; Semi-preparative HPLC chromatogram of the ethyl 
acetate extract from $P$. odoratum aqueous ethanol extract detected at $280 \mathrm{~nm}$; Inhibitory rate of phloridzin (Pz), phloretin (Pt), EA-A, EA-B, EA-1, EA-2, and EA-3 at $5 \mathrm{mM}$ and 25mM glucose transport, respectively, EA-A, EA-B, EA-1, EA-2, EA-3 were isolated from EA by Semi-preparative HPLC chromatogram; QTOF-MS spectra, ${ }^{1} \mathrm{H}$ NMR and ${ }^{13} \mathrm{C}$ NMR of EA-1, EA-2 and EA-3; Details chemical information of Peak EA-1, EA-2 and EA-3.

\section{- ACKNOWLEDGMENTS}

This research was supported by the Unilever Research Colworth Grant (CH-2011-1033), the National Natural Science Foundation of China [No. 81373951] and the China Postdoctoral Science Foundation funded project [No. 2016M601637].

\section{- AUTHOR CONTRIBUTIONS}

H.W., M.I.F., L.A.T., X.G., G.L., M.J.B., and S.W. conceptualized and designed the study. H.W. drafted the manuscript, and M.I.F., D.J.M, L.Z., J.J.O.O., G.L., M.J.B., and S.W. revised it. H.W. and M.I.F. performed biological experiments and data collections. H.W., D.J.M, R.L., J.S., and S.S contributed to bioassay-directed fractionation, structure identification and GC/MS 2-deoxyglucose assay. H.W., L.A.T., and J.J.O.O. contributed to homoisoflavonoids identification by LC-MS/MS. H.W., X.G., L.Z., G.L., M.J.B., and S.W. contributed to TCM herb scoping and preliminary activity assay. All authors contributed to data interpretation, reviewed the manuscript and approved the final version.

\section{Notes}

Two authors (H.W. and M.I.F.) are named inventors on international patent specifications "Edible composition" initially published in 2017 (WO/2017/036926) that contain partial information found in this manuscript. All other authors declare no competing financial interest. 


\section{- Abbreviations Used}

GLUT2, glucose transporter 2; SGLT1, sodium-dependent glucose transporter-1; SAP, sappanintype; FBS, fetal bovine serum; HPLC, high performance liquid chromatography; HR-ESI-MS, highresolution electrospray ionization mass spectrometry; QTOF, quadrupole time-of-flight; UPLC, ultra-performance liquid chromatography; NMR, nuclear magnetic resonance; GC-MS, gas chromatography-mass Spectrometer; EA-1, 5,7-dihydroxy-3-(4'-hydroxybenzyl)-6-methylchroman4-one; EA-2, 5,7-dihydroxy-3-(4'-hydroxybenzyl)-6-methyl-8-methoxychroman-4-one; EA-3, 5,7dihydroxy-3-(4'-hydroxybenzyl)-6, 8-dimethylchroman-4-one; MOA, methylophiopogonanone A; MOB, methylophiopogonanone B; PE, petroleum ether; EA: ethyl acetate; tCGT, total cumulative glucose transport

\section{- REFERENCES}

1. Eckel, R. H.; Alberti, K. G. M. M.; Grundy, S. M.; Zimmet, P. Z., The metabolic syndrome. Medical Clinics of North America 2005, 365, (9468), 1415-1428.

2. Node, K.; Inoue, T., Postprandial hyperglycemia as an etiological factor in vascular failure. Cardiovascular Diabetology 2009, 8, (1), 1-10.

3. Wu, J.; Shi, S.; Wang, H.; Wang, S., Mechanisms underlying the effect of polysaccharides in the treatment of type 2 diabetes: A review. Carbohydrate Polymers 2016, 144, 474-494.

4. IDF Diabetes Atlas 7th edition www.idf.org/diabetesatlas www.idf.org/diabetesatlas.

5. Malchoff, C. D., Diagnosis and Classification of Diabetes Mellitus. Diabetes Care 2013, 36, (Suppl 1), S67-S74.

6. Drozdowski, L. A.; Thomson, A. B., Intestinal sugar transport. World Journal of Gastroenterology 2006, 12, (11), 1657-1670.

7. Bell, K. J.; Smart, C. E.; Steil, G. M.; Brand-Miller, J. C.; King, B.; Wolpert, H. A., Impact of fat, protein, and glycemic index on postprandial glucose control in type 1 diabetes: implications for intensive diabetes management in the continuous glucose monitoring era. Diabetes Care 2015, 38, (6), 1008-1015.

8. Hinnen, D. A., Therapeutic Options for the Management of Postprandial Glucose in Patients With 
Type 2 Diabetes on Basal Insulin. Clinical Diabetes A Publication of the American Diabetes Association 2015, 33, (4), 175-180.

9. Zheng, Y.; Scow, J. S.; Duenes, J. A.; Sarr, M. G., Mechanisms of glucose uptake in intestinal cell lines: role of GLUT2. Surgery 2012, 151, (1), 13-25.

10. Thorens, B.; Cheng, Z. Q.; Brown, D.; Lodish, H. F., Liver glucose transporter: a basolateral protein in hepatocytes and intestine and kidney cells. The American journal of physiology 1990, 259, (1), 279-285.

11. Kellett, G. L.; Brotlaroche, E., Apical GLUT2: a major pathway of intestinal sugar absorption. Diabetes 2005, 54, (10), 3056-3062.

12. Wright, E. M.; Martín, M. G.; Turk, E., Intestinal absorption in health and disease--sugars. Best Practice \& Research Clinical Gastroenterology 2004, 17, (6), 943-956.

13. Kwon, O.; Eck, P.; Chen, S.; Corpe, C. P.; Lee, J. H.; Kruhlak, M.; Levine, M., Inhibition of the intestinal glucose transporter GLUT2 by flavonoids. Faseb Journal Official Publication of the Federation of American Societies for Experimental Biology 2007, 21, (2), 366-377.

14. Ross, J. A.; Kasum, C. M., Dietary flavonoids: bioavailability, metabolic effects, and safety. Annu Rev Nutr. Annual Review of Nutrition 2002, 22, (1), 19-34.

15. Zhang, H.; Yang, F.; Qi, J.; Song, X. C.; Hu, Z. F.; Zhu, D. N.; Yu, B. Y., Homoisoflavonoids from the fibrous roots of Polygonatum odoratum with glucose uptake-stimulatory activity in 3T3-L1 adipocytes. Journal of Natural Products 2010, 73, (4), 548-552.

16. Miura, T.; Kato, A., The difference in hypoglycemic action between polygonati rhizoma and polygonati officinalis rhizoma. Biological \& Pharmaceutical Bulletin 1995, 18, (11), 1605-1606.

17. Wei, D.; Hai, B. S.; Ma, H.; Yan, B. M.; Tong, J. L.; Wei, W., Homoisoflavanones from Polygonatum odoratum rhizomes inhibit advanced glycation end product formation. Archives of Pharmacal Research 2010, 33, (5), 669-674.

18. Zhou, X.; Liang, J.; Zhang, Y.; Zhao, H.; Guo, Y.; Shi, S., Separation and purification of $\alpha-$ glucosidase inhibitors from Polygonatum odoratum by stepwise high-speed counter-current chromatography combined with Sephadex LH-20 chromatography target-guided by ultrafiltrationHPLC screening. Journal of Chromatography B 2015, 985, 149-154.

19. Wang, H.; Shi, S.; Wang, S., Can highly cited herbs in ancient Traditional Chinese medicine formulas and modern publications predict therapeutic targets for diabetes mellitus? Journal of 
Ethnopharmacology 2018, 213, 101-110.

20. Berry, M., John; Fowler, M., Ian; Heath, A., David, An edible composition comprising resveratrol and flavonoid monoglucoside. In 2014.

21. Hubatsch, I.; Ragnarsson, E. G.; Artursson, P., Determination of drug permeability and prediction of drug absorption in Caco-2 monolayers. Nature Protocols 2006, 2, (9), 2111-2119.

22. Yamashita, S.; Konishi, K.; Yamazaki, Y.; Taki, Y.; Sakane, T.; Sezaki, H.; Furuyama, Y., New and better protocols for a short-term Caco-2 cell culture system. Journal of Pharmaceutical Sciences 2002, 91, (3), 669-679.

23. Hu, Y. C.; Luo, Y. D.; Li, L.; Joshi, M. K.; Lu, Y. H., In vitro investigation of 2',4'-dihydroxy-6'methoxy-3',5'-dimethylchalcone for glycemic control. Journal of Agricultural and Food Chemistry 2012, 60, (42), 10683-10688.

24. Wu, T.; Yang, M.; Wei, H. F.; He, S. H.; Wang, S. C.; Ji, G., Application of Metabolomics in Traditional Chinese Medicine Differentiation of Deficiency and Excess Syndromes in Patients with Diabetes Mellitus. Evidence-based Complementary and Alternative Medicine 2012, 2012, (3), 968083. 25. Rafi, M. M.; Vastano, B. C., Identification of a structure specific Bcl-2 phosphorylating homoisoflavone molecule from Vietnamese coriander (Polygonatum odoratum) that induces apoptosis and G2/M cell cycle arrest in breast cancer cell lines. Food Chemistry 2007, 104, (1), 332-340.

26. Wang, D.; Li, D.; Zhu, W.; Peng, P., A new C-methylated homoisoflavanone and triterpenoid from the rhizomes of Polygonatum odoratum. Natural Product Research 2009, 23, (6), 580-589.

27. Lin, L. G.; Liu, Q. Y.; Ye, Y., Naturally occurring homoisoflavonoids and their pharmacological activities. Planta Medica 2014, 80, (13), 1053-1066.

28. Zhou, X.; Yuping, Z.; Zhao, H.; Liang, J.; Zhang, Y.; Shi, S., Antioxidant homoisoflavonoids from Polygonatum odoratum. Food Chemistry 2015, 186, 63-68.

29. Kalsi, K. K.; Baker, E. H.; Medina, R. A.; Rice, S.; Wood, D. M.; Ratoff, J. C.; Philips, B. J.; Baines, D. L., Apical and basolateral localisation of GLUT2 transporters in human lung epithelial cells. Pflügers Archiv - European Journal of Physiology 2008, 456, (5), 991-1003.

30. Yim, S.; Malhotra, A.; Veves, A., Antioxidants and CVD in diabetes: Where do we stand now? Current Diabetes Reports 2007, 7, (1), 8-13.

31. Li, W. L.; Zheng, H. C.; Bukuru, J.; De, K. N., Natural medicines used in the traditional Chinese medical system for therapy of diabetes mellitus. Journal of Ethnopharmacology 2004, 92, 1-21. 
32. Kikkawa, R., Chronic complications in diabetes mellitus. British Journal of Nutrition 2000, 84 (S2), S183-S185.

33. Guo, H.; Zhao, H.; Kanno, Y.; Li, W.; Mu, Y.; Kuang, X.; Inouye, Y.; Koike, K.; Jiang, H.; Bai, H., A dihydrochalcone and several homoisoflavonoids from Polygonatum odoratum are activators of adenosine monophosphate-activated protein kinase. Bioorganic \& Medicinal Chemistry Letters 2013, 23, (11), 3137-3139.

34. Dong, W.; Shi, H. H.; Miao, Y. B.; Liu, T. J.; Wang, W., Homoisoflavanones from Polygonatum odoratum rhizomes inhibit advanced glycation end product formation. Archives of Pharmacal Research 2010, 33, (5), 669-674.

35. Lan, G.; Chen, H.; Wang, Z.; Zhang, W.; Zhang, L., Extraction of Polygonatum odoratum polysaccharides using response surface methodology and preparation of a compound beverage. Carbohydrate Polymers 2011, 86, (3), 1175-1180. 


\section{Figure captions}

Figure 1. The chemical profile of the homoisoflavonoids in the Polygonatum odoratum, among of them 9: EA-1, 10: EA-2, 11: EA-3.

Figure 2. The structures of SAP homoisoflavonoids. The code name indicates the notation used throughout.

Figure 3. SAP homoisoflavonoids inhibition of glucose and 2-deoxyglucose transport. (A) Inhibitory rate of EA-1, EA-2, EA-3, MOA, MOB and phloretin (Pt) on 25mM glucose and 25mM 2deoxyglucose transport at the concentration of $15 \mu \mathrm{M}(\mathrm{n}=3$, NS: no significant difference, $* \mathrm{P}<0.05)$; (B) SAP homoisoflavonoids inhibition of glucose transport at $25 \mathrm{mM}$ glucose in Caco-2 cells $(\mathrm{n}=3)$.

Figure 4. Inhibitory rate of homoisoflavonoids (EA-1, EA-2, EA-3, MOA, and MOB), flavonoids (apigenin (A), luteolin $(\mathrm{L})$, quercetin $(\mathrm{Q})$, naringenin $(\mathrm{N})$, hesperetin $(\mathrm{H})$, and genistein $(\mathrm{G})$ ) and phloretin $(\mathrm{Pt})$ on $25 \mathrm{mM}$ glucose transport at the concentration of $15 \mu \mathrm{M}(\mathrm{n}=3)$, the significant differences between groups are indicated by different letters a-d at $\mathrm{P}<0.05$.

Figure 5. The total cumulative glucose transport across differentiated Caco- 2 monolayers in the presence or absence of a SGLT1 inhibitor for the first $15 \mathrm{~min}$ in $5 \mathrm{mM}$ D-glucose and subsequently in the presence or absence of a GLUT2 inhibitor in $25 \mathrm{mM}$ D-glucose for the remaining $45 \mathrm{~min}$. A: Cumulative glucose transport by phloridzin $(\mathrm{Pz}, 300 \mu \mathrm{M}) \&$ phloretin $(\mathrm{Pt}, 125 \mu \mathrm{M})$; B: Cumulative glucose transport by tectoridin $(\mathrm{T}, 300 \mu \mathrm{M})$ \& EA-1 $(5 \mu \mathrm{M})$; C: Cumulative glucose transport by luteolin-7-glucoside $(\mathrm{L} 7 \mathrm{G}, 300 \mu \mathrm{M}) \&$ EA-1 (2.5 $\mu \mathrm{M})$; D: Cumulative glucose transport by myrtillin chloride $(\mathrm{MC}, 300 \mu \mathrm{M}) \& \mathrm{MOB}(5 \mu \mathrm{M})$; E: Cumulative glucose transport by naringenin-7-Oglucoside $(\mathrm{N} 7 \mathrm{G}, 300 \mu \mathrm{M}) \& \mathrm{MOB}(5 \mu \mathrm{M}) ; \mathbf{F}$ : Cumulative glucose transport by kaempferol-3-glucoside 
$(\mathrm{K} 3 \mathrm{G}, 150 \mu \mathrm{M}) \& \mathrm{EA}-2(10 \mu \mathrm{M})$; G: Cumulative glucose transport by tectoridin $(\mathrm{T}, 300 \mu \mathrm{M}) \& \mathrm{MOA}$ $(5 \mu \mathrm{M})$; H: Cumulative glucose transport by apigenin-8-C-glucoside $(\mathrm{A} 8 \mathrm{G}, 300 \mu \mathrm{M}) \& \mathrm{EA}-3(2.5 \mu \mathrm{M})$, the significant differences between groups are indicated by different letters a-d at $\mathrm{P}<0.05$, $(\mathrm{n}=3)$ 
Table 1. Glucose transport inhibition of ethanol extract of $P$. odoratum and its bioassay directed fractions

\begin{tabular}{ccc}
\hline Samples $(200 \mu \mathrm{g} / \mathrm{mL})$ & $\begin{array}{c}\text { \% Glucose transport inhibition } \\
5 \mathrm{mM} \text { D-Glucose }\end{array}$ & $\begin{array}{c}\text { \% Glucose transport inhibition } \\
25 \text { mM D-Glucose }\end{array}$ \\
\hline Ethanol extract (EE) & $71.1 \pm 3.2$ & $48.6 \pm 3.3$ \\
Petroleum ether Fraction (PE) & $75.4 \pm 0.2$ & $51.8 \pm 1.1$ \\
Ethyl acetate fraction (EA) & $98.9 \pm 0.5$ & $58.6 \pm 3.6$ \\
1-Butanol fraction (1-But) & $48.0 \pm 2.6$ & $17.2 \pm 0.1$ \\
Water fraction (Water) & $7.4 \pm 1.3$ & $3.3 \pm 1.5$ \\
& & \\
EA-A & $29.6 \pm 2.3$ & $7.4 \pm 3.0$ \\
EA-B & $65.4 \pm 2.2$ & $41.9 \pm 7.6$ \\
EA-1 & $90.7 \pm 1.4$ & $66.6 \pm 5.2$ \\
EA-2 & $89.9 \pm 0.1$ & $63.0 \pm 2.9$ \\
EA-3 & $91.2 \pm 0.5$ & $67.4 \pm 5.9$ \\
MOA & $39.3 \pm 2.2$ & $27.7 \pm 3.7$ \\
MOB & $46.2 \pm 2.0$ & $30.6 \pm 3.2$ \\
Phloridzin & $31.4 \pm 1.5$ & $14.2 \pm 1.1$ \\
Phloretin & $90.4 \pm 2.2$ & $58.2 \pm 1.8$ \\
\hline
\end{tabular}

Phloridzin and pure homoisoflavonoids were tested at $300 \mu \mathrm{M}$ and Phloretin was tested at $150 \mu \mathrm{M}$. The other samples were tested at $200 \mu \mathrm{g} / \mathrm{mL}$, EA-A, EA-B, EA-1, EA-2, EA-3 were isolated from EA. 
<smiles>[R]c1ccc(CC2COc3c([R])c(O)c([R])c(O)c3C2=O)c([R])c1</smiles><smiles>Cc1c(O)cc2c(c1O)C(=O)C(C(O)c1ccccc1)CO2</smiles><smiles>[125IH]</smiles>
$1 \quad \mathrm{R}_{1}=\mathrm{H}$
$\mathrm{R}_{2}=\mathrm{CH}_{3} \quad \mathrm{R}_{3}=\mathrm{OH} \quad \mathrm{R}_{4}=\mathrm{OH}$
$2 \mathrm{R}_{1}=\mathrm{H}$
$\mathrm{R}_{2}=\mathrm{CH}_{3} \quad \mathrm{R}_{3}=\mathrm{H} \quad \mathrm{R}_{4}=\mathrm{OH}$
$3 \mathrm{R}_{1}=\mathrm{H}$
$\mathrm{R}_{2}=\mathrm{H} \quad \mathrm{R}_{3}=\mathrm{OH} \quad \mathrm{R}_{4}=\mathrm{OCH}_{3}$
$4 \quad \mathrm{R}_{1}=\mathrm{H}$
$\mathrm{R}_{2}=\mathrm{H} \quad \mathrm{R}_{3}=\mathrm{OH} \quad \mathrm{R}_{4}=\mathrm{OH}$
$5 \mathrm{R}_{1}=\mathrm{H}$
$\mathrm{R}_{2}=\mathrm{H} \quad \mathrm{R}_{3}=\mathrm{H} \quad \mathrm{R}_{4}=\mathrm{OH}$
$6 \mathrm{R}_{1}=\mathrm{H}$
$\mathrm{R}_{2}=\mathrm{OCH}_{3} \quad \mathrm{R}_{3}=\mathrm{OH} \quad \mathrm{R}_{4}=\mathrm{OCH}_{3}$
$7 \quad \mathrm{R}_{1}=\mathrm{OCH}_{3} \quad \mathrm{R}_{2}=\mathrm{CH}_{3} \quad \mathrm{R}_{3}=\mathrm{OH} \quad \mathrm{R}_{4}=\mathrm{OH}$
$8 \quad \mathrm{R}_{1}=\mathrm{OCH}_{3} \quad \mathrm{R}_{2}=\mathrm{H} \quad \mathrm{R}_{3}=\mathrm{H} \quad \mathrm{R}_{4}=\mathrm{OCH}_{3}$
$9 \quad \mathrm{R}_{1}=\mathrm{CH}_{3} \quad \mathrm{R}_{2}=\mathrm{H} \quad \mathrm{R}_{3}=\mathrm{H} \quad \mathrm{R}_{4}=\mathrm{OH}$
$10 \mathrm{R}_{1}=\mathrm{CH}_{3} \quad \mathrm{R}_{2}=\mathrm{OCH}_{3} \quad \mathrm{R}_{3}=\mathrm{H} \quad \mathrm{R}_{4}=\mathrm{OH}$
$11 \mathrm{R}_{1}=\mathrm{CH}_{3} \quad \mathrm{R}_{2}=\mathrm{CH}_{3} \quad \mathrm{R}_{3}=\mathrm{H} \quad \mathrm{R}_{4}=\mathrm{OH}$
$12 \mathrm{R}_{1}=\mathrm{CH}_{3} \quad \mathrm{R}_{2}=\mathrm{OCH}_{3} \quad \mathrm{R}_{3}=\mathrm{H} \quad \mathrm{R}_{4}=\mathrm{OCH}_{3}$
$13 \mathrm{R}_{1}=\mathrm{CH}_{3} \quad \mathrm{R}_{2}=\mathrm{CH}_{3} \quad \mathrm{R}_{3}=\mathrm{OH}_{4}=\mathrm{OCH}_{3}$<smiles>COc1ccc(CC2COc3c(C)c(O)c(C)c(O)c3C2=O)cc1O</smiles><smiles>[R]c1c(O)c(C)c(O)c2c1OCC(O)(Cc1ccc(O)cc1)C2=O</smiles>

$16 \mathrm{R}=\mathrm{CH}_{3} \quad 17 \mathrm{R}=\mathrm{OCH}_{3}$<smiles>Cc1cc(C)c2c(c1)C(=O)/C(=C/c1ccc(O)cc1)CO2</smiles><smiles>CC1(C)O[C@H](Oc2cc(O)c3c(c2)OC/C(=C\c2ccc(O)cc2)C3=O)[C@H](O)[C@@H]1O</smiles>

Figure 1 


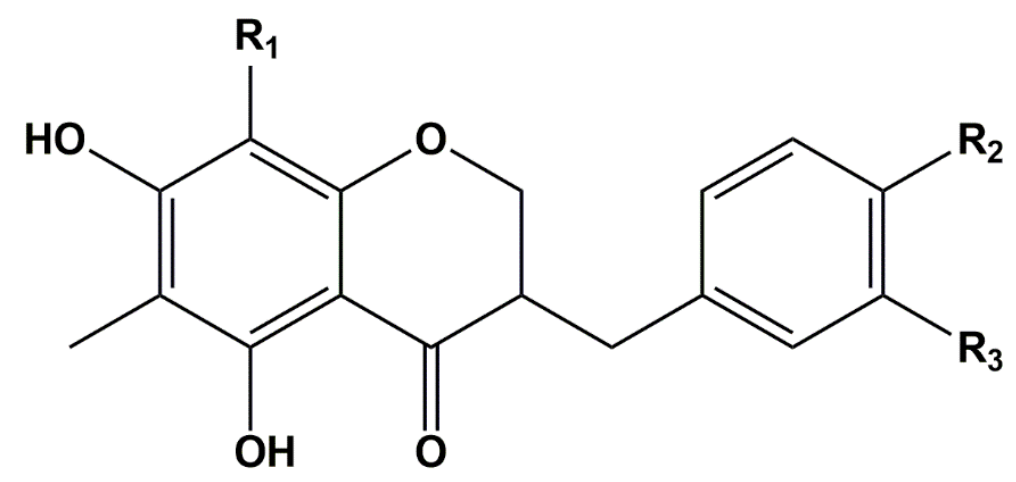

\begin{tabular}{llll}
\hline Code name & $\mathrm{R}_{1}$ & $\mathbf{R}_{2}$ & $\mathbf{R}_{3}$ \\
\hline EA-1 & $\mathrm{H}$ & $\mathrm{OH}$ & $\mathrm{H}$ \\
EA-2 & $\mathrm{OCH}_{3}$ & $\mathrm{OH}$ & $\mathrm{H}$ \\
EA-3 & $\mathrm{CH}_{3}$ & $\mathrm{OH}$ & $\mathrm{H}$ \\
MOA & $\mathrm{CH}_{3}$ & $\mathrm{R}_{2}-\mathrm{O}-\mathrm{CH}_{2}-\mathrm{O}-\mathrm{R}_{3}$ & \\
MOB & $\mathrm{CH}_{3}$ & $\mathrm{OCH}_{3}$ & $\mathrm{H}$ \\
\hline
\end{tabular}

Figure 2. 

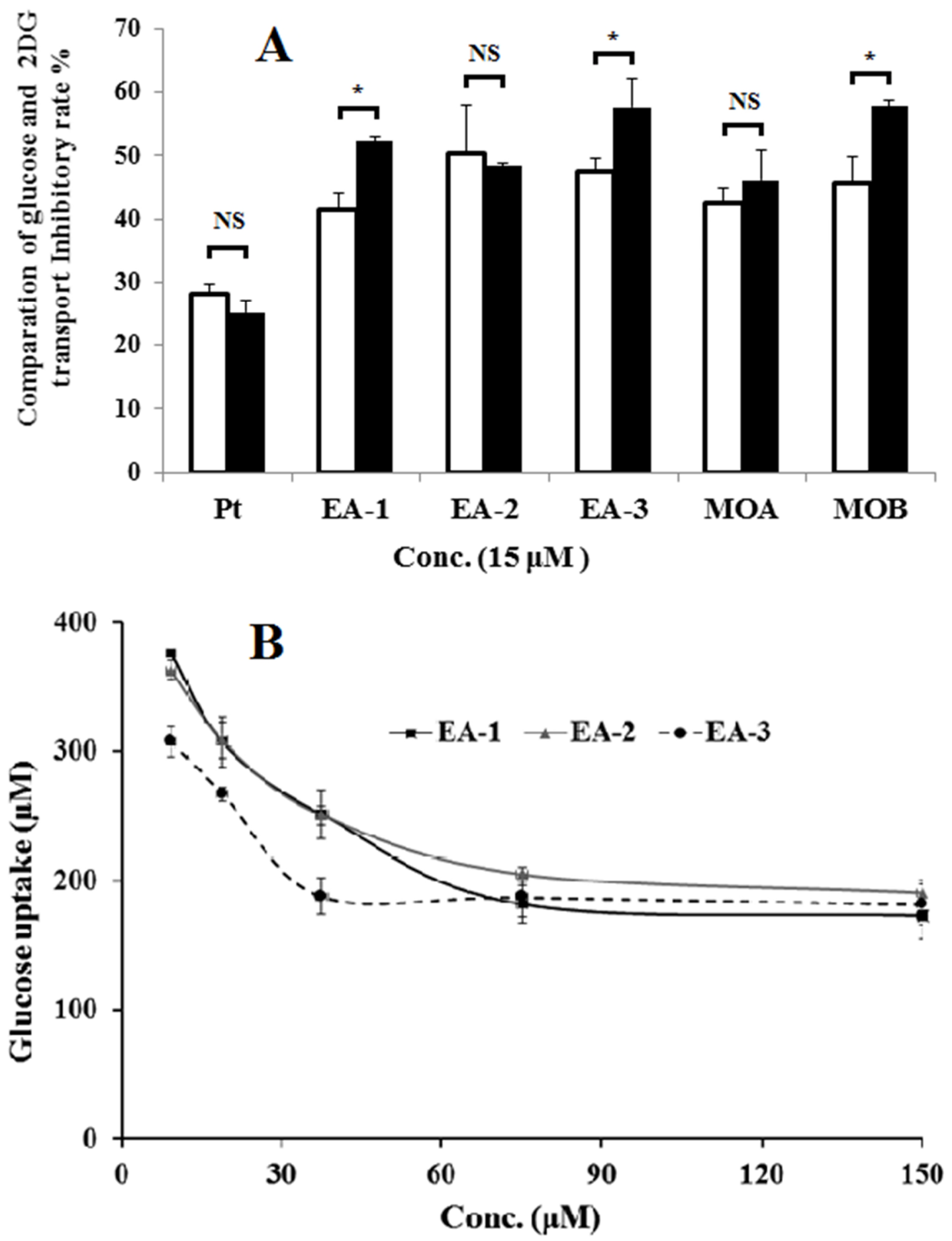

Figure 3. 


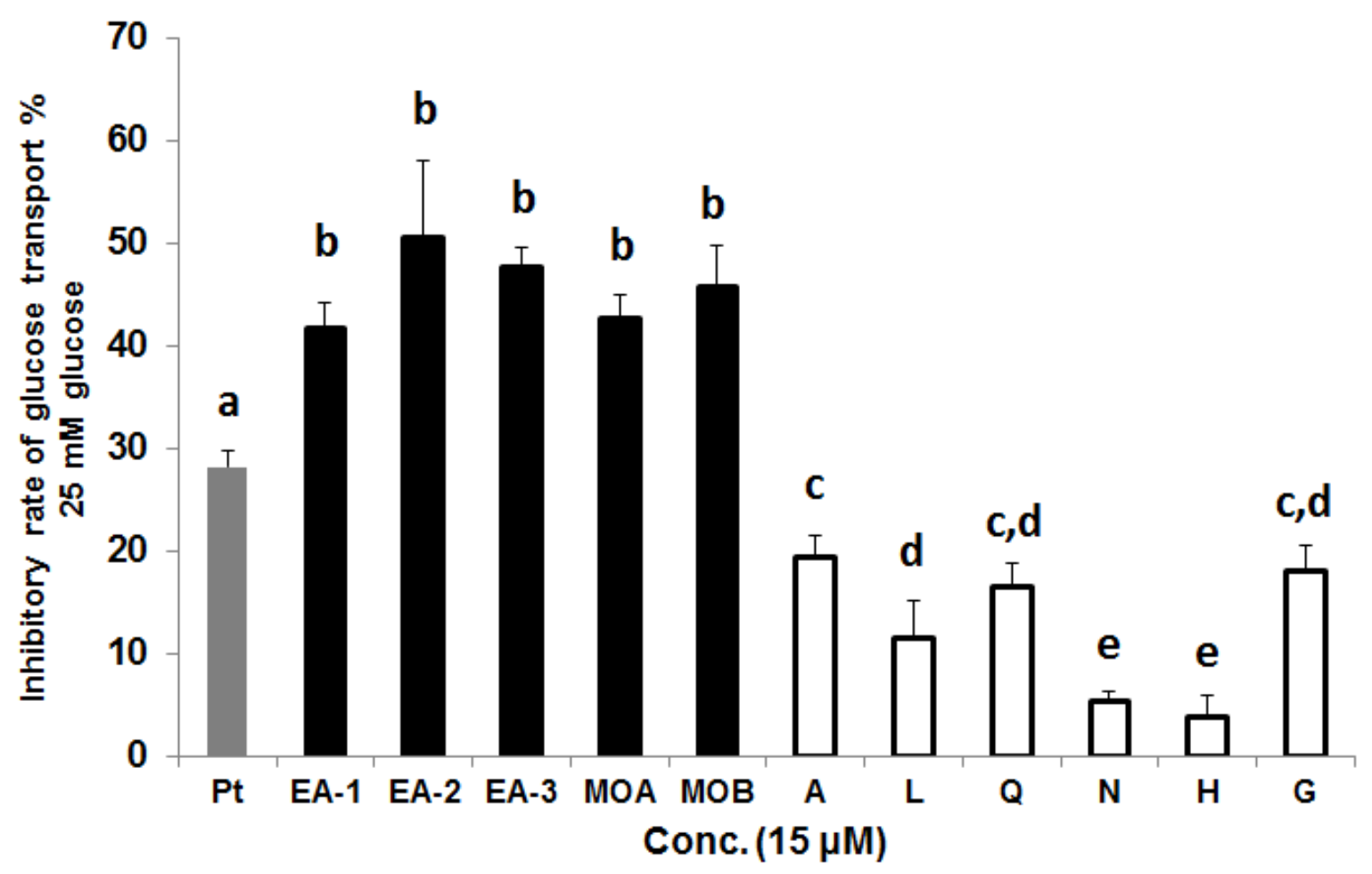

Figure 4. 


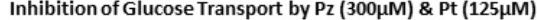
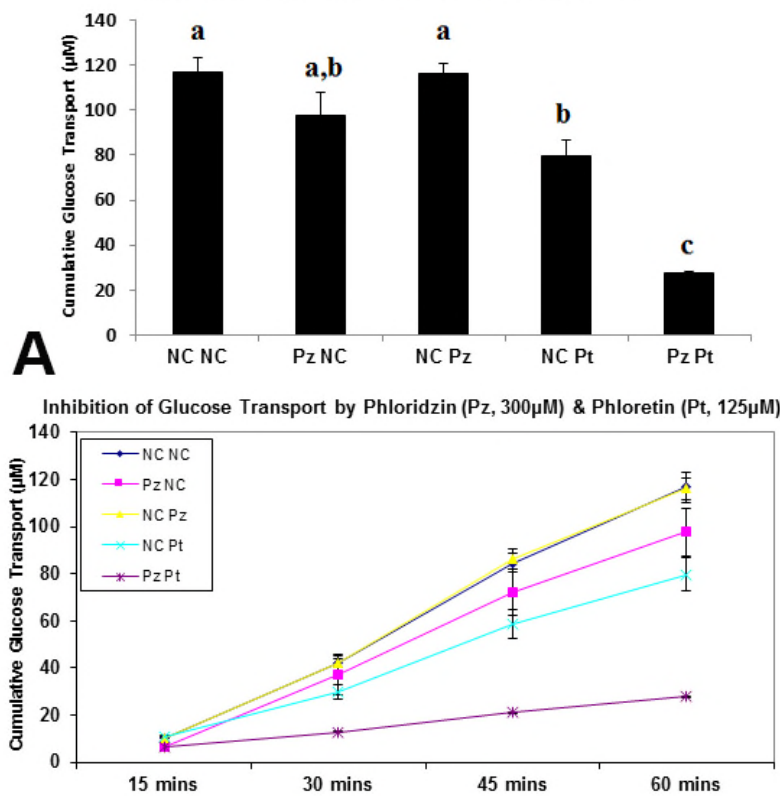

Inhibition of Glucose Transport by L7G (300uM) \& EA-1 (10uM)

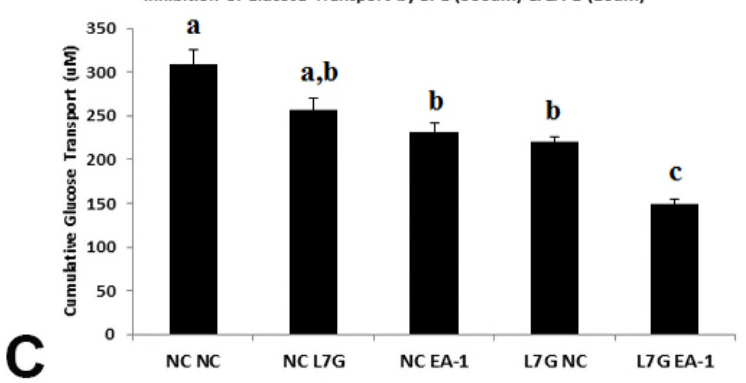

Inhibition of Glucose Transport by Luteolin-7-glucoside (L7G,300uM) \& EA-1(10uM)

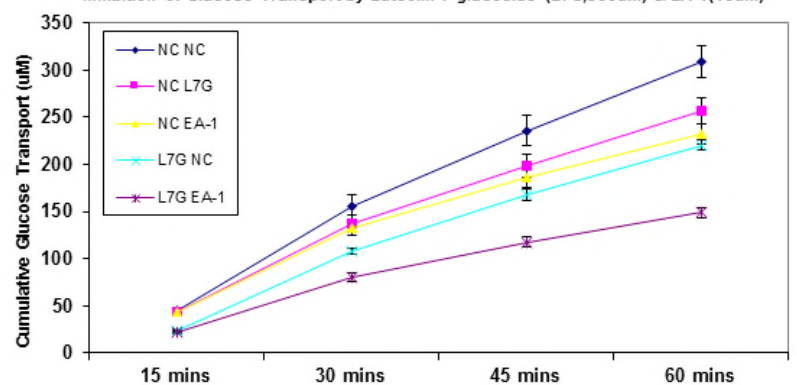

hibition of Glucose Transport by Tectoricin(300uM) \& EA-1 (10uM)
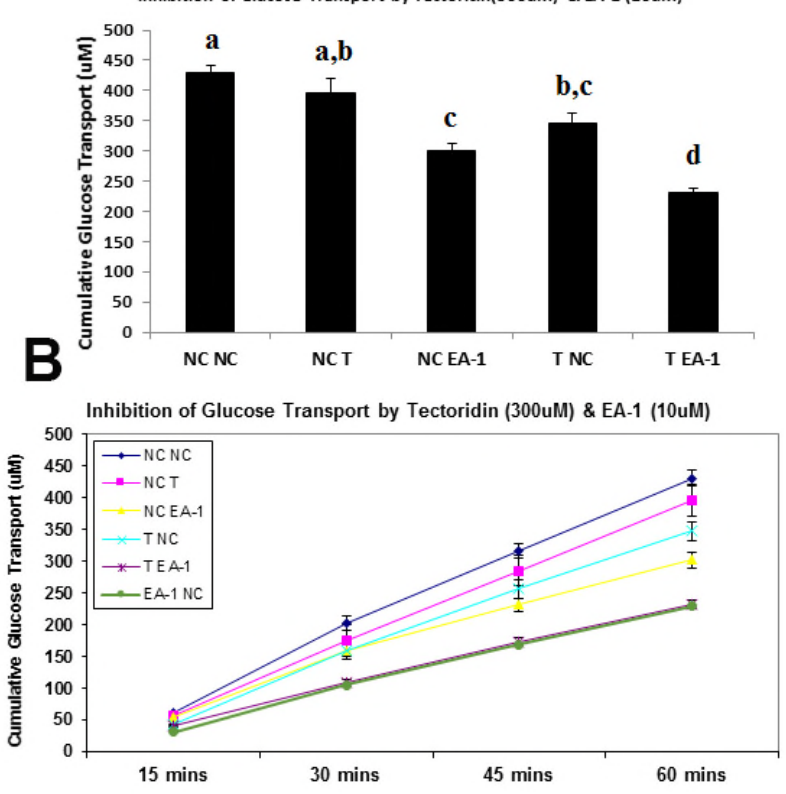

Inhibition of Glucose Transport by MC (300uM) \& MOB (5uM)

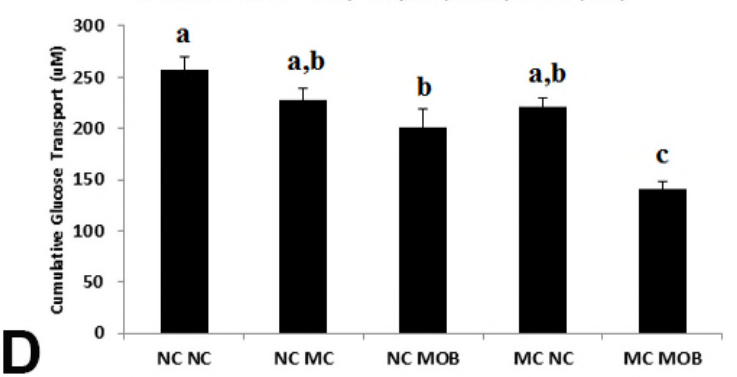

Inhibition of Glucose Transport by Naringenin-7-0-glucoside (N7G, 300uM) \& MOB (5uM)

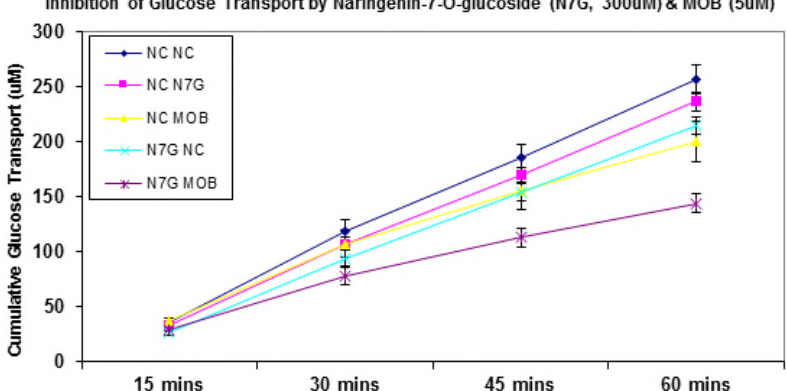



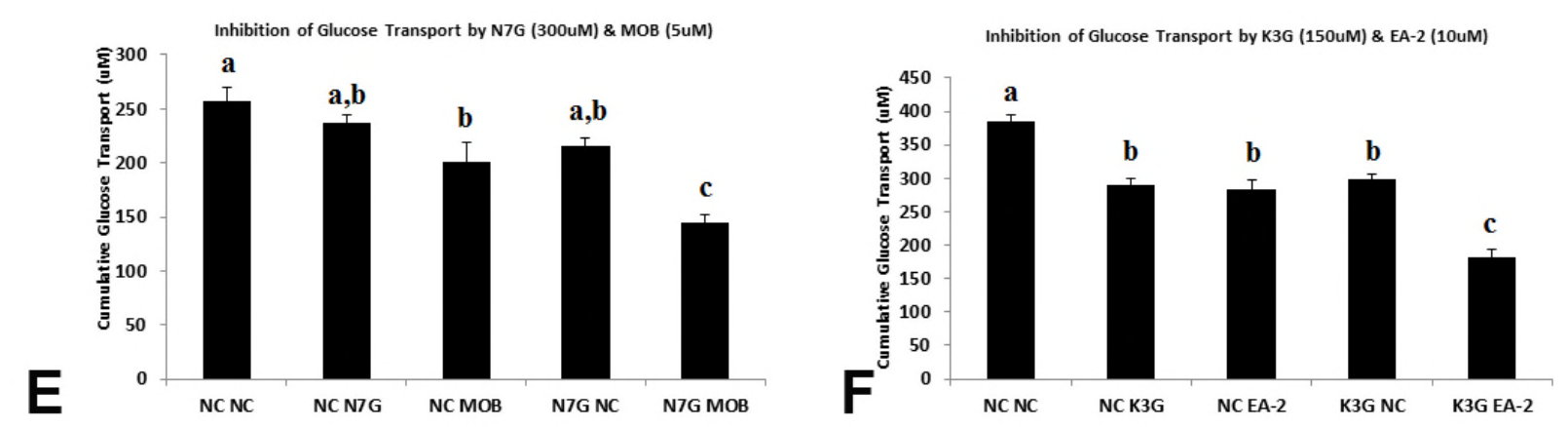

Inhibition of Glucose Transport by Naringenin-7-O-glucoside (N7G, 300uM) \& MOB (5uM)
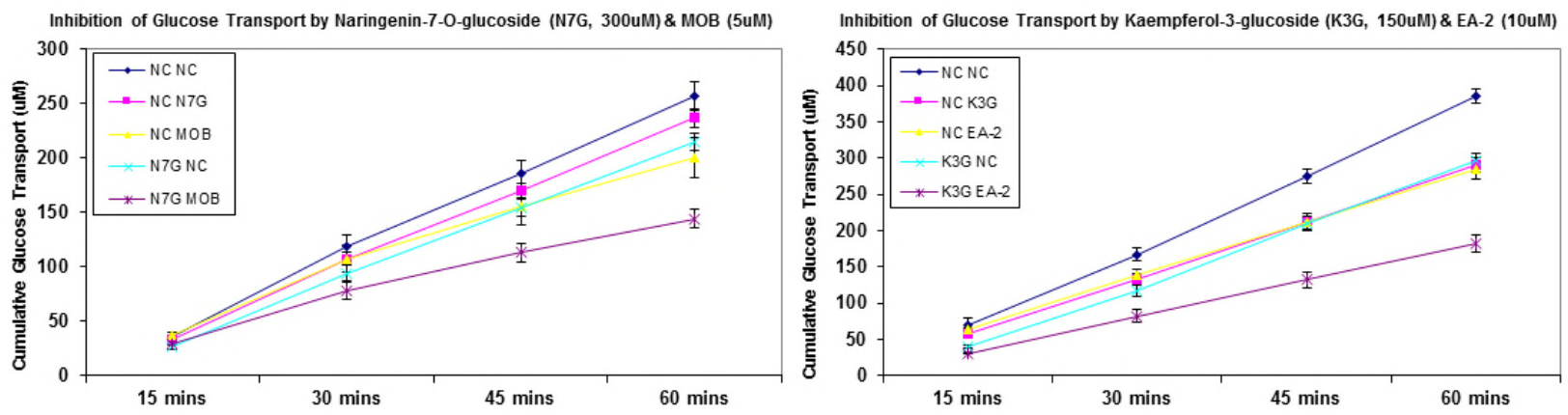

Inhibition of Glucose Transport by Tectoricin(300uM) \& MOA (5uM)
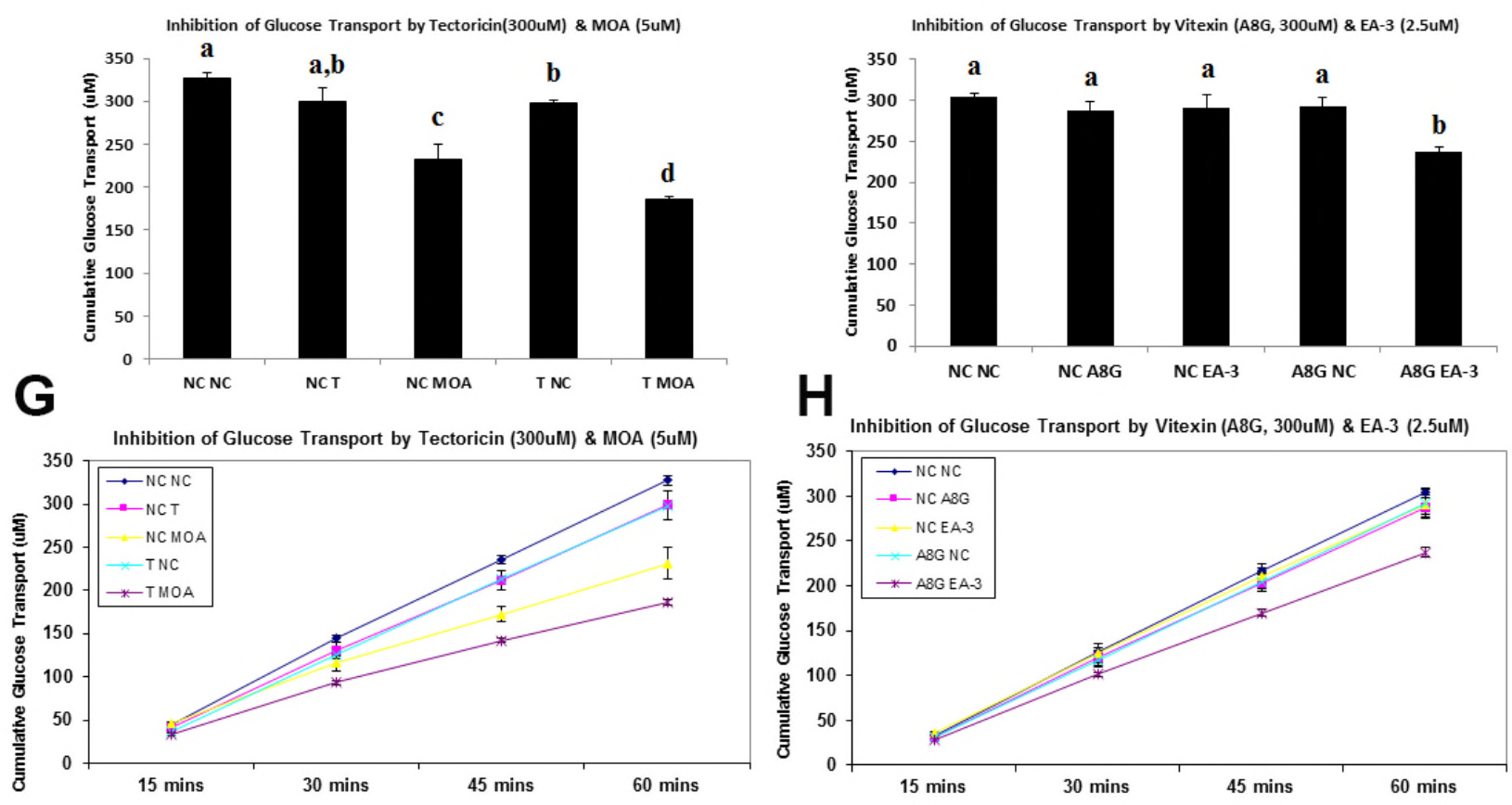

Inhibition of Glucose Transport by Vitexin (A8G, 300uM) \& EA-3 (2.5uM)

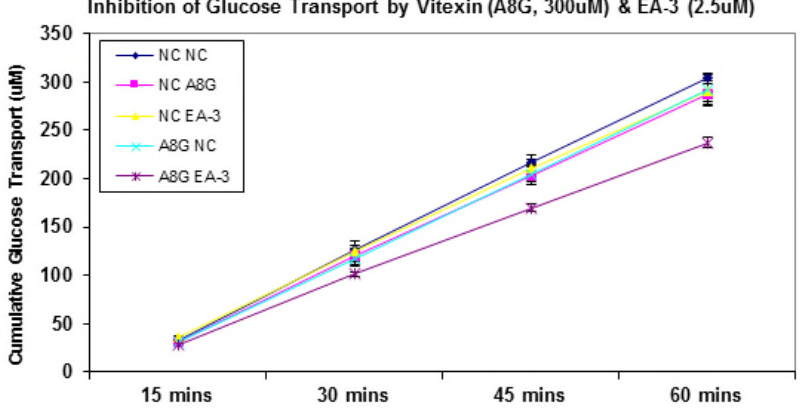

Figure 5. 


\section{Graphical Abstract}

Homoisoflavonoids, the potent GLUT2 inhibitors, have a synergistic effect with flavonoids monoglucosides (SGLT1 inhibitors)

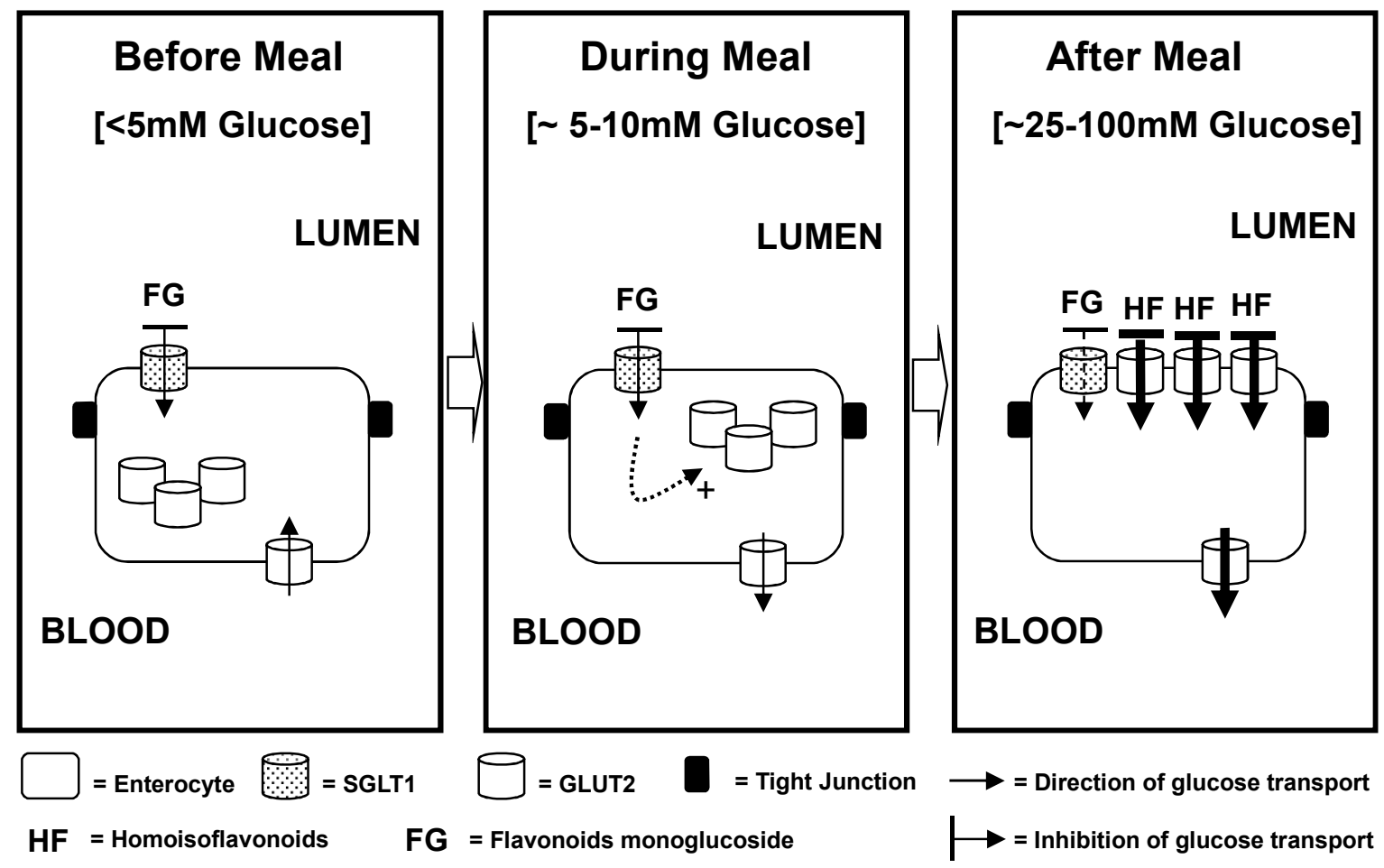




\section{Supporting Information}

Table S1. Glucose transport inhibitory effect and $\mathrm{IC}_{50}$ of homoisoflavonoids and flavonoids

\begin{tabular}{ccc}
\hline Homoisoflavonoids & $\mathrm{IC}_{50}(\mu \mathrm{M}), 5 \mathrm{mM}$ Glucose & $\mathrm{IC}_{50}(\mu \mathrm{M}), 25 \mathrm{mM}$ Glucose \\
\hline EA-1 & 18.5 & 47.4 \\
EA-2 & 14.3 & 54.5 \\
EA-3 & 8.6 & 21.1 \\
MOA & Unknown & Unknown \\
MOB & Unknown & Unknown \\
Apigenin & 122.8 & 259.5 \\
Luteolin & 30.3 & 62.4 \\
Quercetin & 32.9 & 41.6 \\
Naringenin & 176.7 & 295.1 \\
Hesperetin & 121.6 & 162.7 \\
Genistein & 97.77 & 157.8 \\
\hline
\end{tabular}




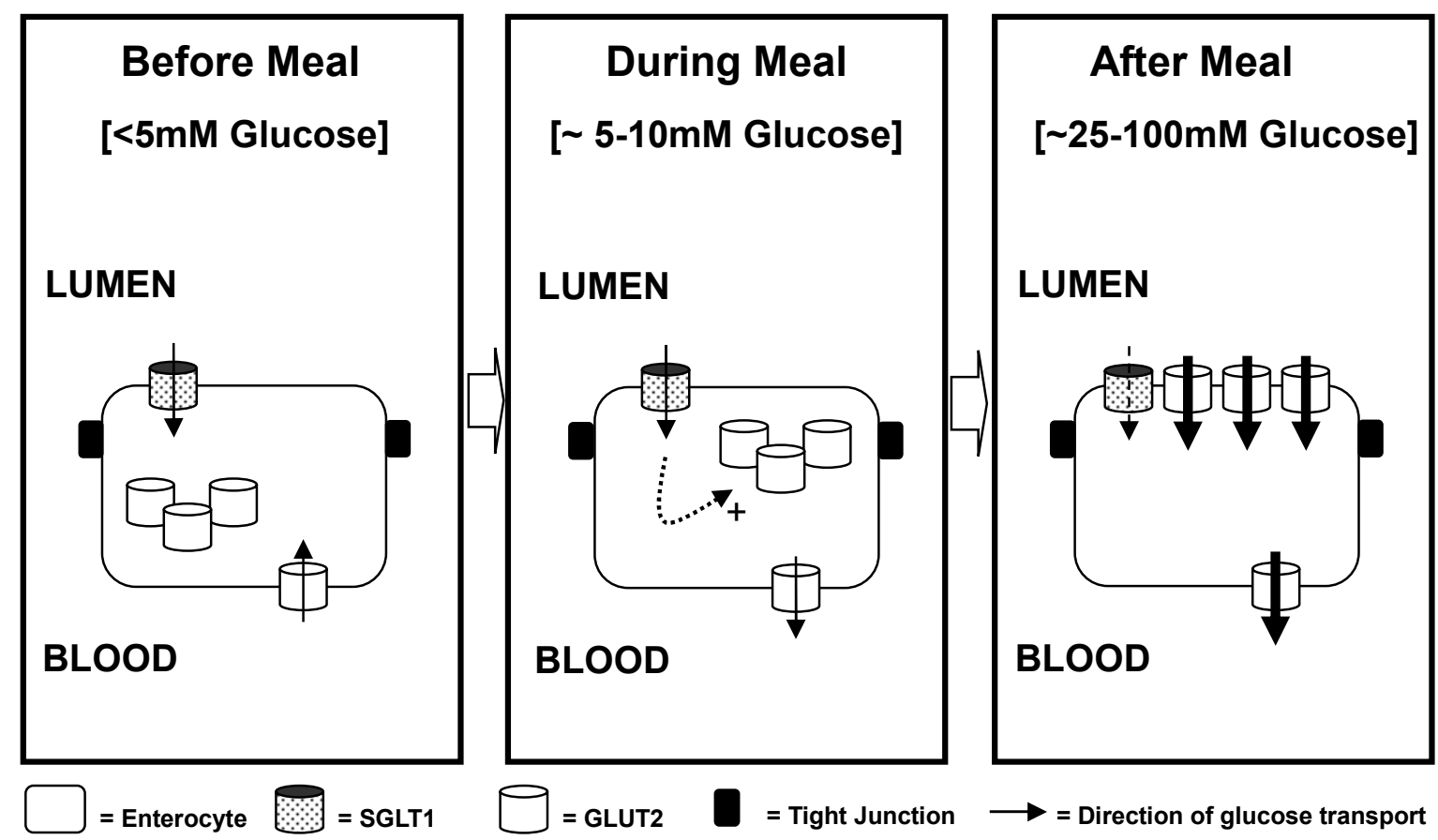

Figure S1. A model of the glucose concentration timeline during a meal 


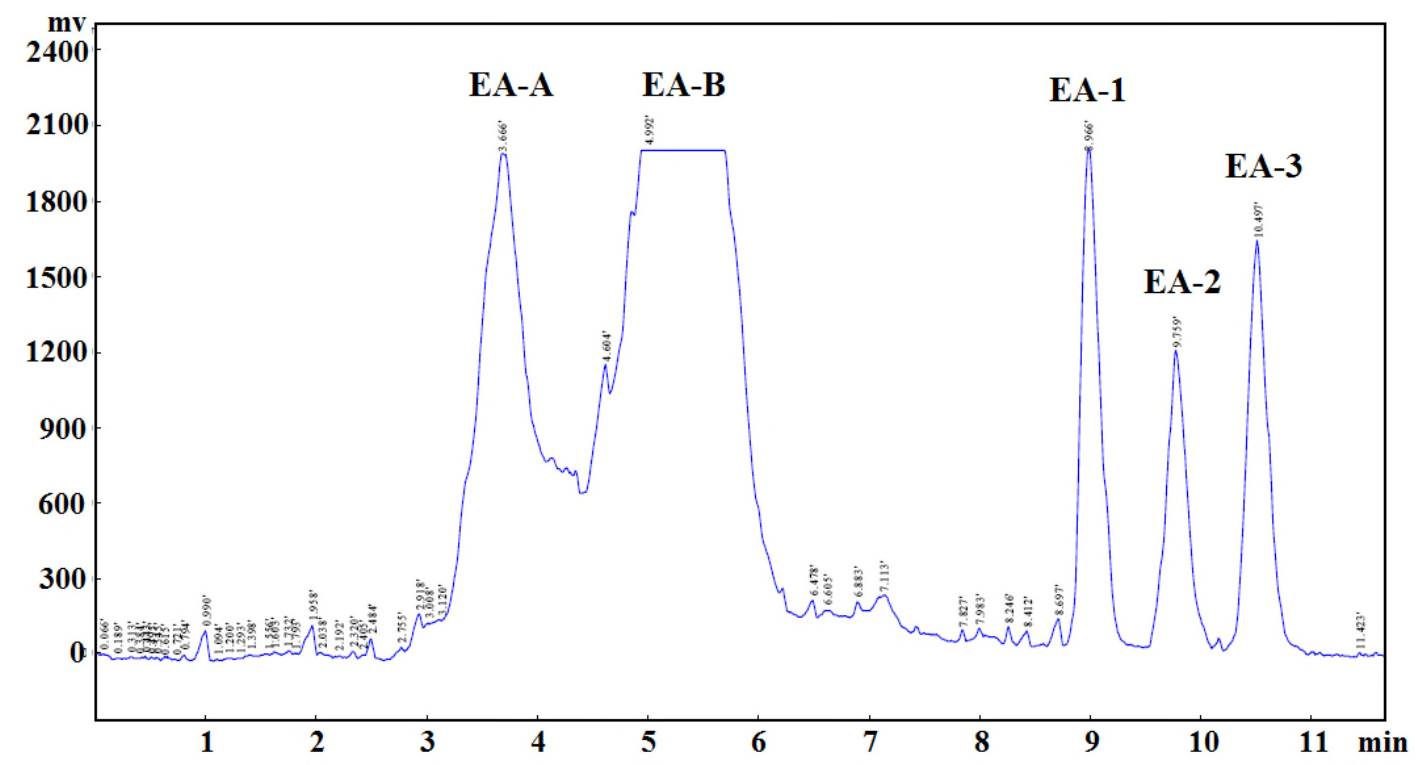

Figure S2a Semi-preparative HPLC chromatogram of the ethyl acetate extract from $P$. odoratum aqueous ethanol extract detected at $280 \mathrm{~nm}$.

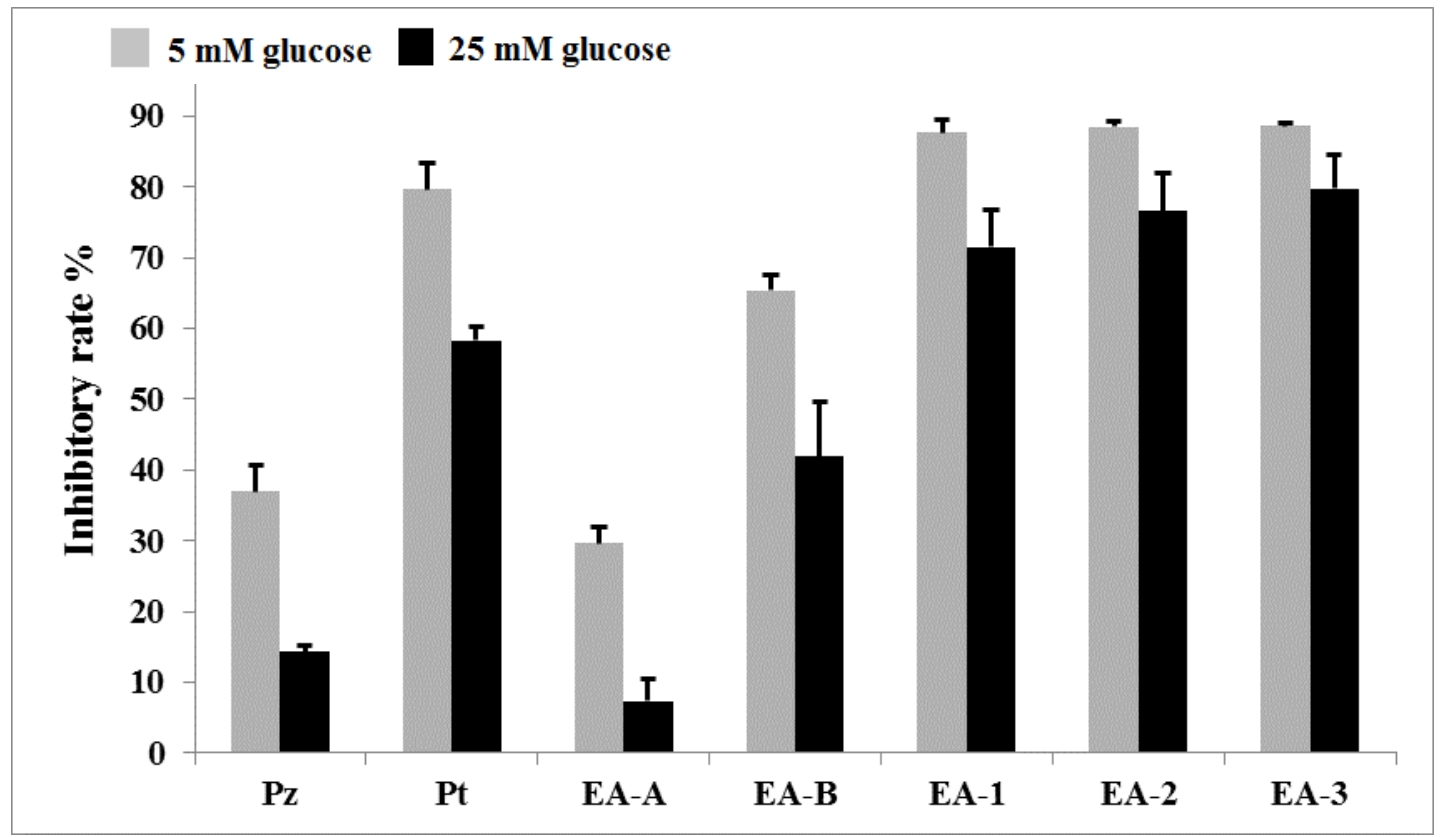

Figure S2b Inhibitory rate of phloridzin (Pz), phloretin (Pt), EA-A, EA-B, EA-1, EA-2, and EA-3 at $5 \mathrm{mM}$ and $25 \mathrm{mM}$ glucose transport, respectively. Phloretin was tested at $150 \mu \mathrm{M}$ and phloridzin was tested at $300 \mu \mathrm{M}$. The other samples were tested at $200 \mu \mathrm{g} / \mathrm{mL}, \mathrm{EA}-\mathrm{A}, \mathrm{EA}-\mathrm{B}, \mathrm{EA}-1$, EA-2, EA-3 were isolated from EA by Semi-preparative HPLC chromatogram. 
A

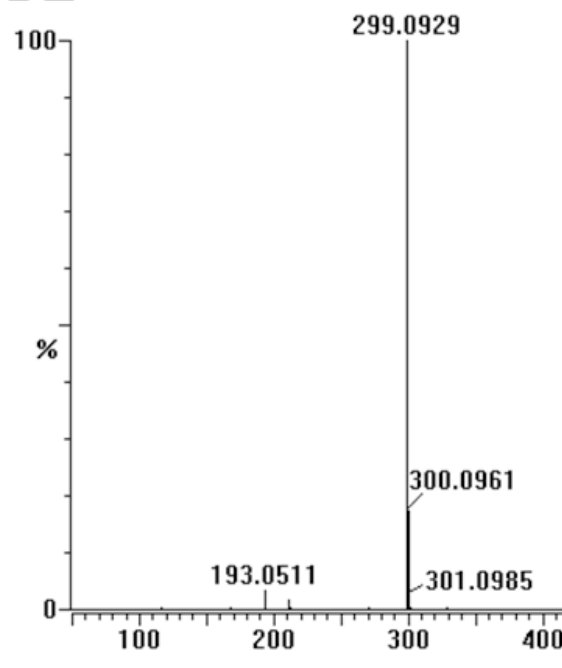

1: TOF MS ES-

$1.31 \mathrm{e} 7$

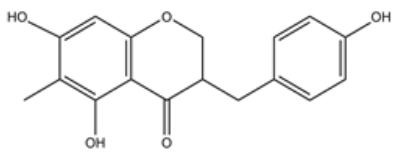

EA-1

\section{B}

100

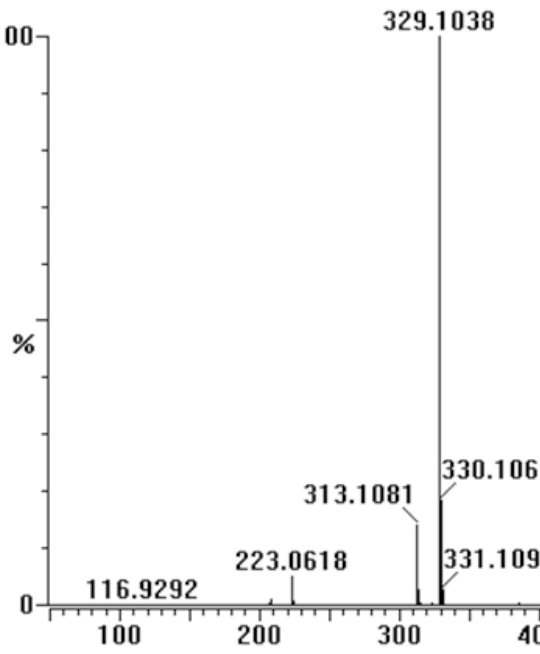

1: TOF MS ES-

$1.16 \mathrm{e} 7$

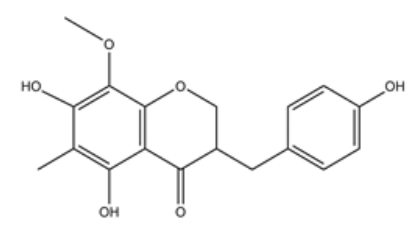

EA-2

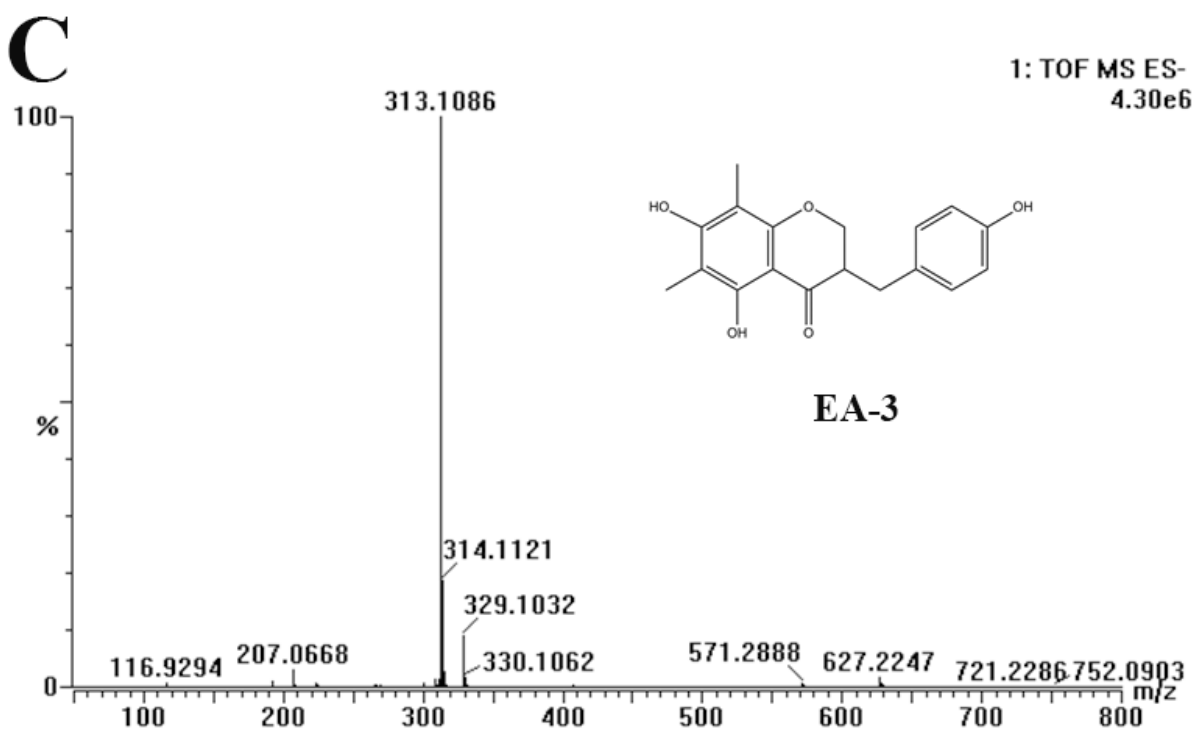

Figure S3 QTOF-MS spectra for EA-1, EA-2 and EA-3. 


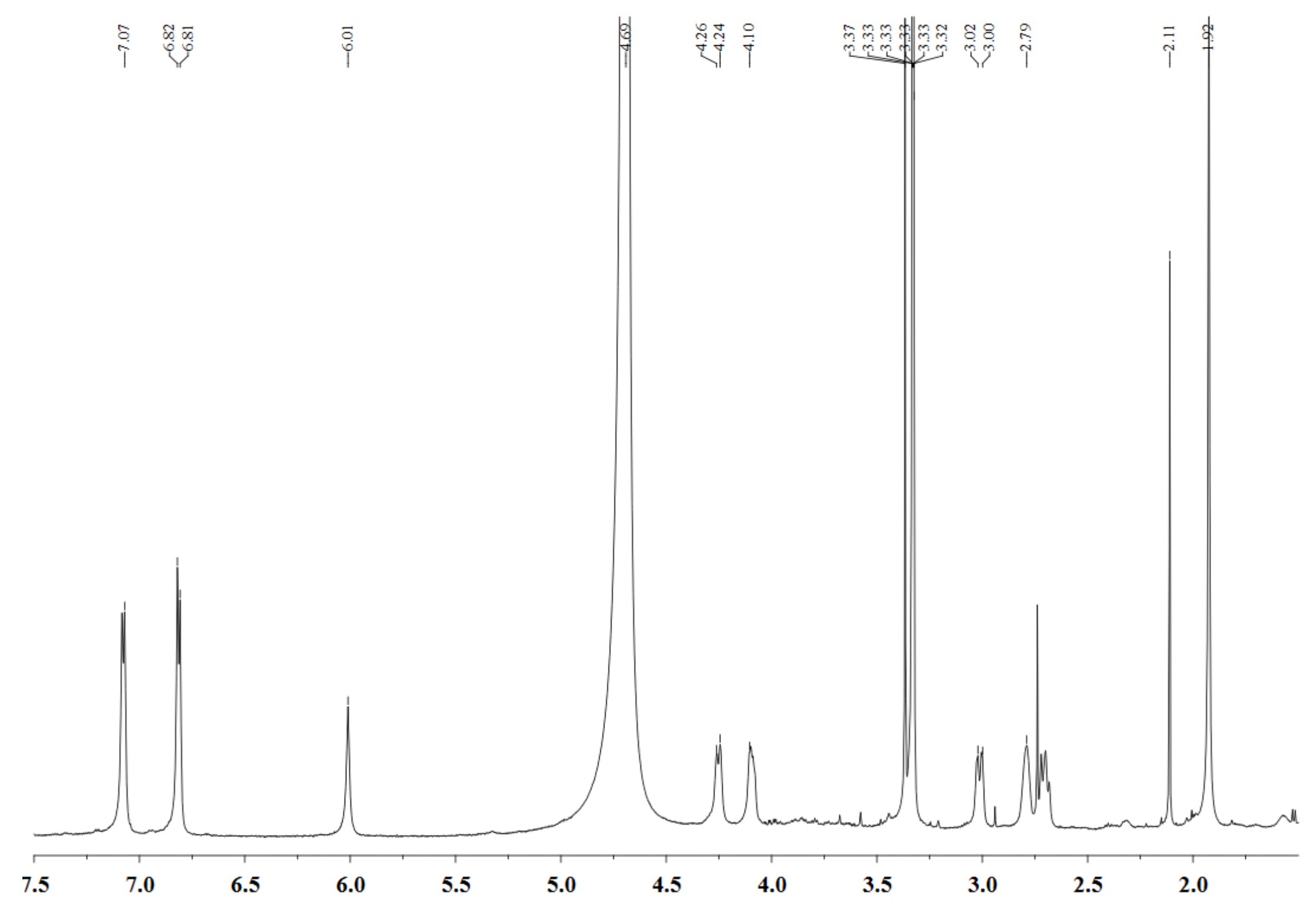

Figure S4 ${ }^{1} \mathrm{H}$ NMR of EA-1 (ppm, $\left.600 \mathrm{MHz}, \mathrm{CD}_{3} \mathrm{OD}\right)$ 


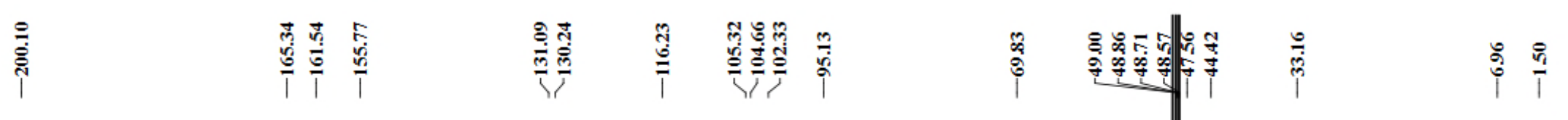

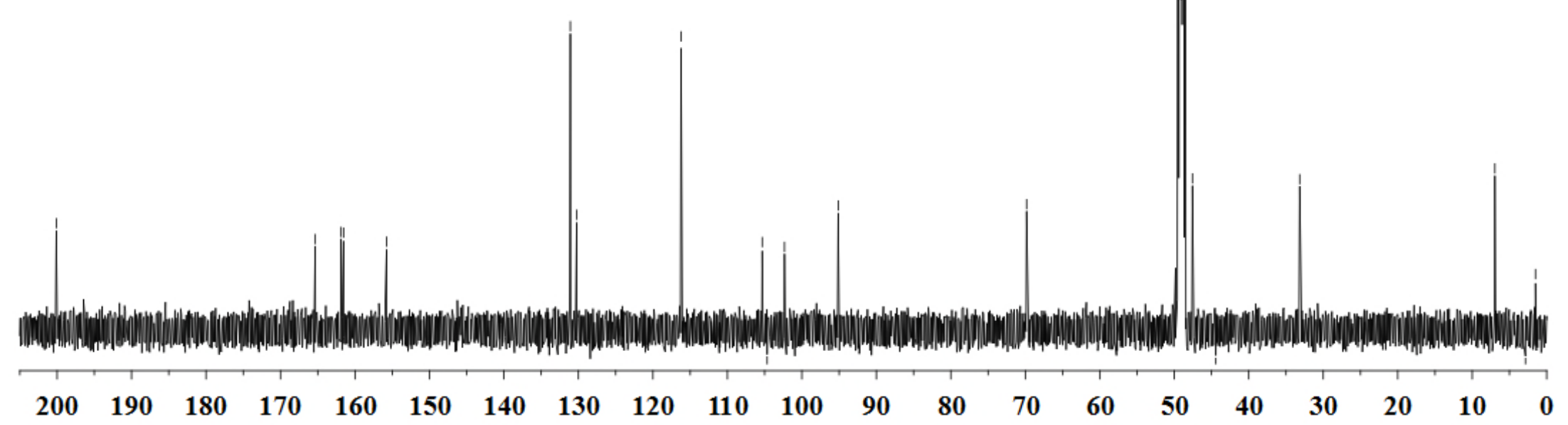

Figure $\mathrm{S5}^{13} \mathrm{C}$ NMR of EA-1 (ppm, 600MHz, $\left.\mathrm{CD}_{3} \mathrm{OD}\right)$ 


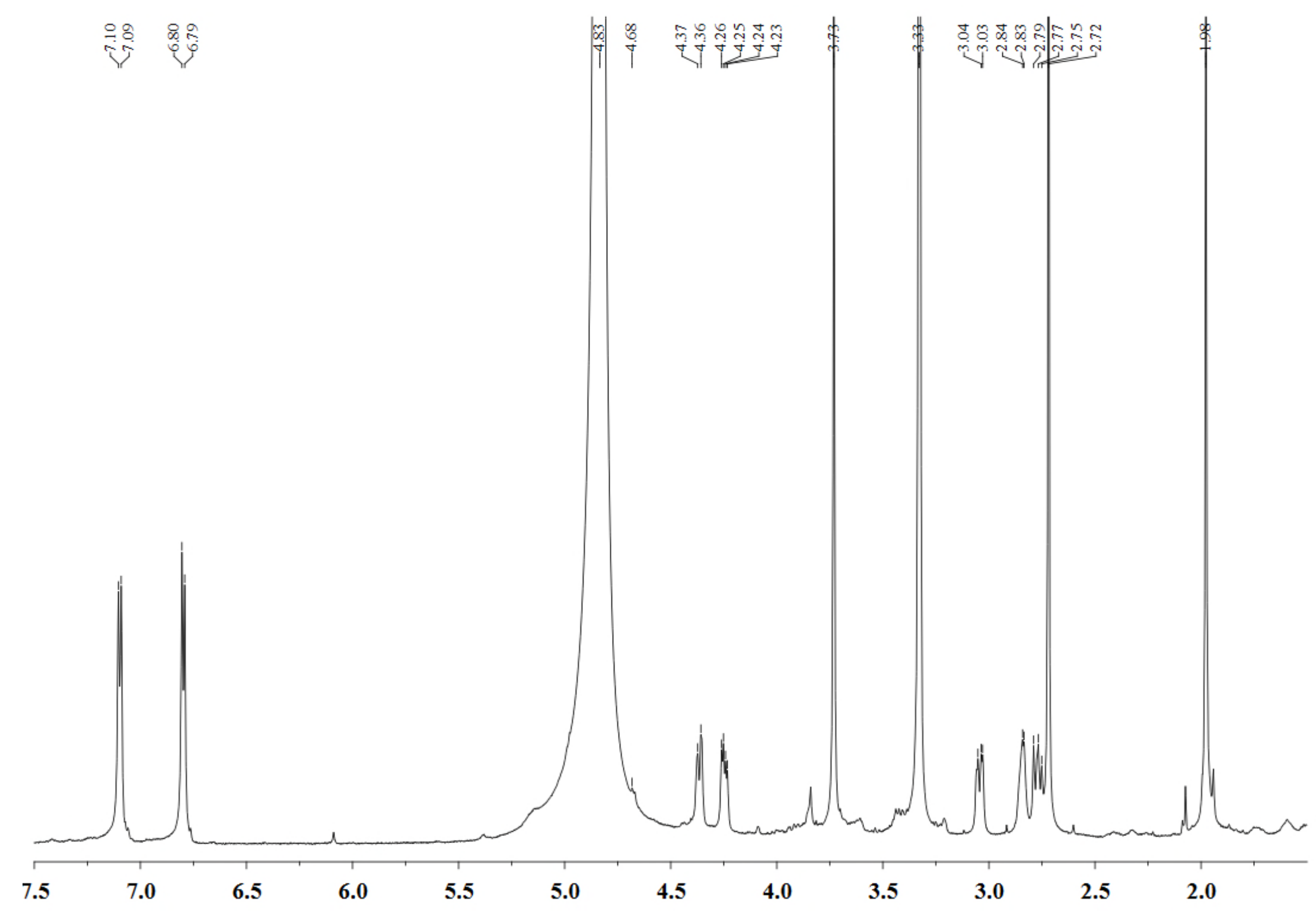

Figure S6 ${ }^{1} \mathrm{H}$ NMR of EA-2 (ppm, 600MHz, $\left.\mathrm{CD}_{3} \mathrm{OD}\right)$ 


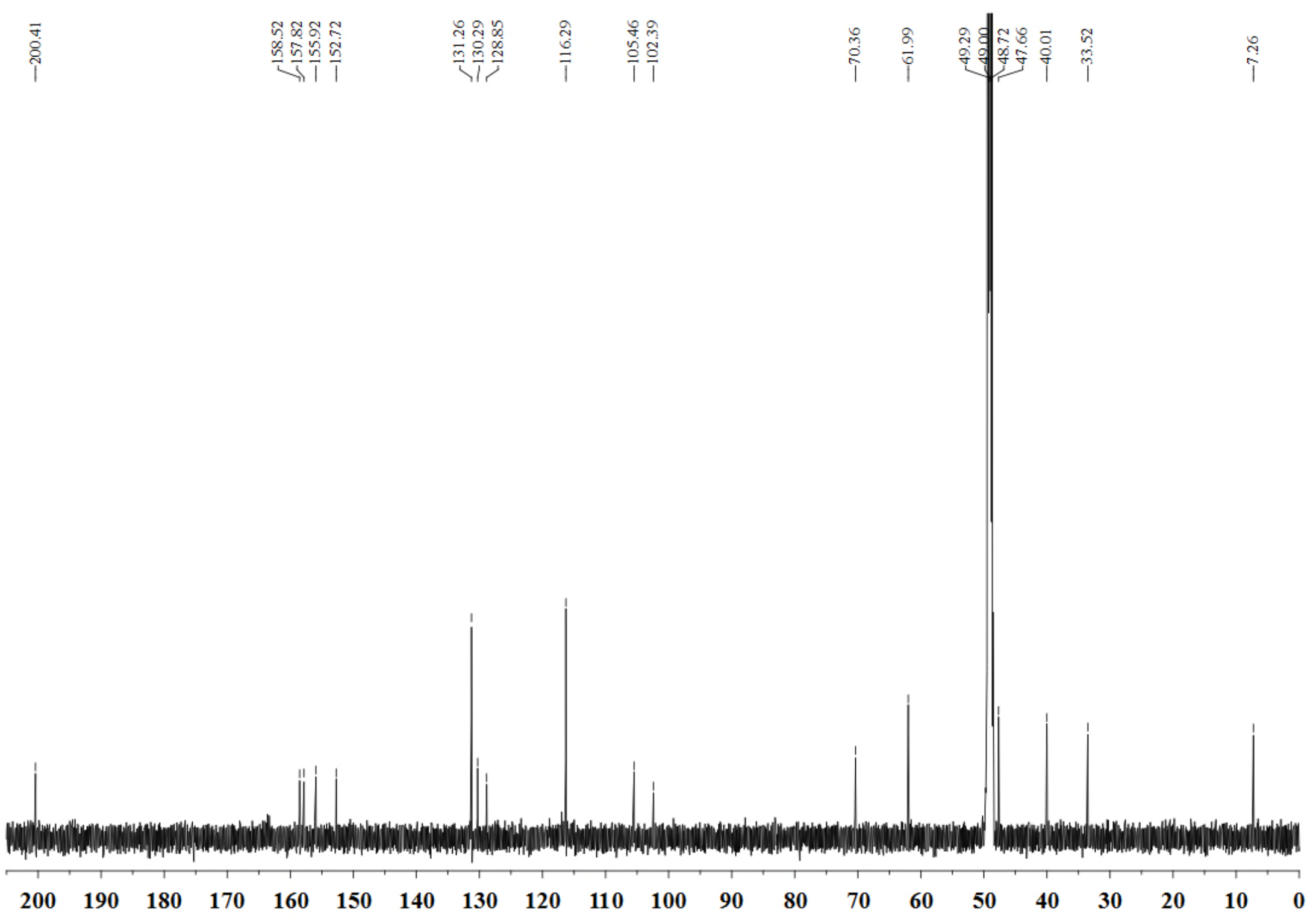

Figure $\mathbf{S} 7{ }^{13} \mathrm{C}$ NMR of EA-2 (ppm, $\left.600 \mathrm{MHz}, \mathrm{CD}_{3} \mathrm{OD}\right)$ 


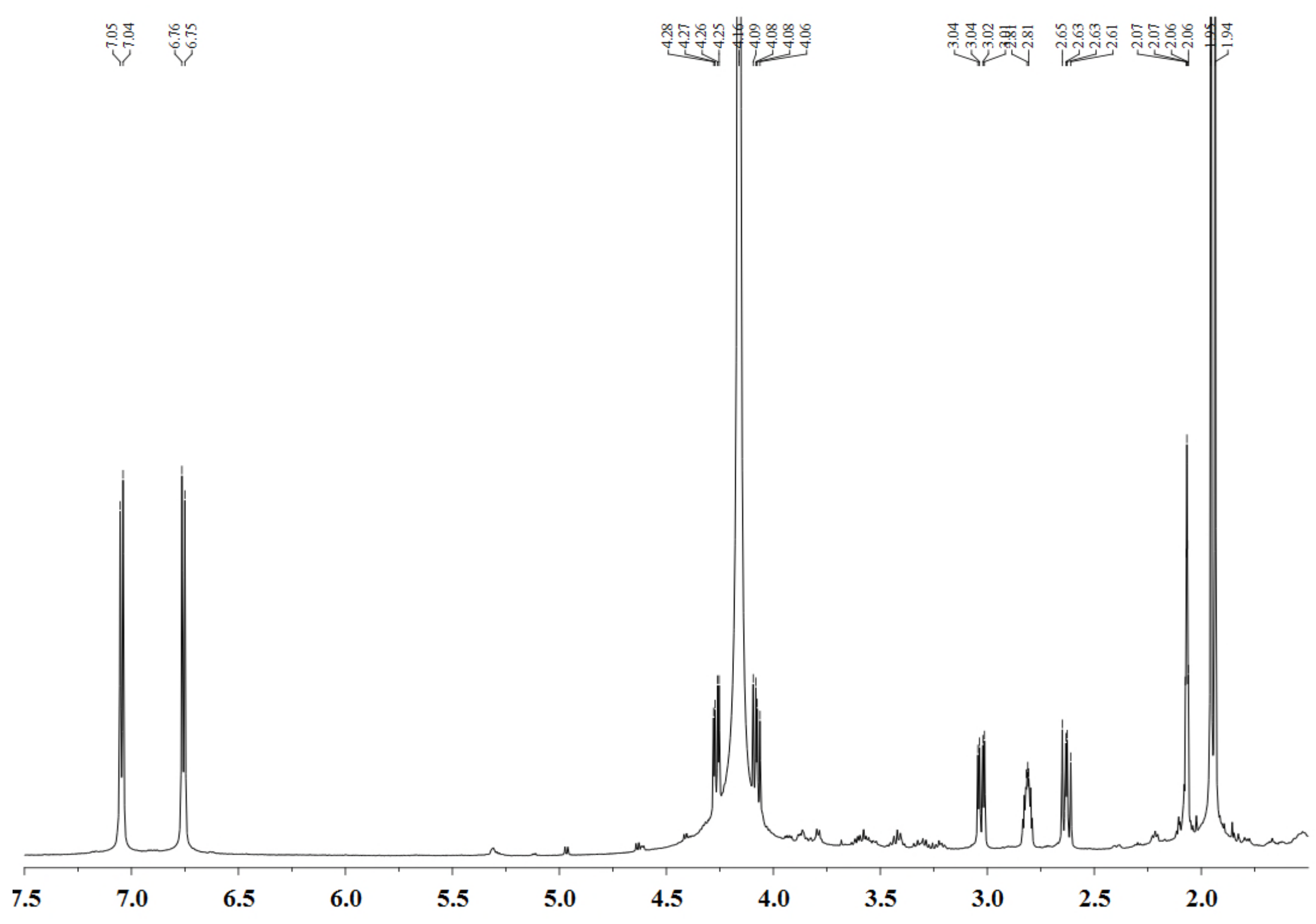

Figure $\mathbf{S 8}{ }^{1} \mathrm{H}$ NMR of EA-3 (ppm, $600 \mathrm{MHz}, \mathrm{CD}_{3} \mathrm{OD}$ ) 


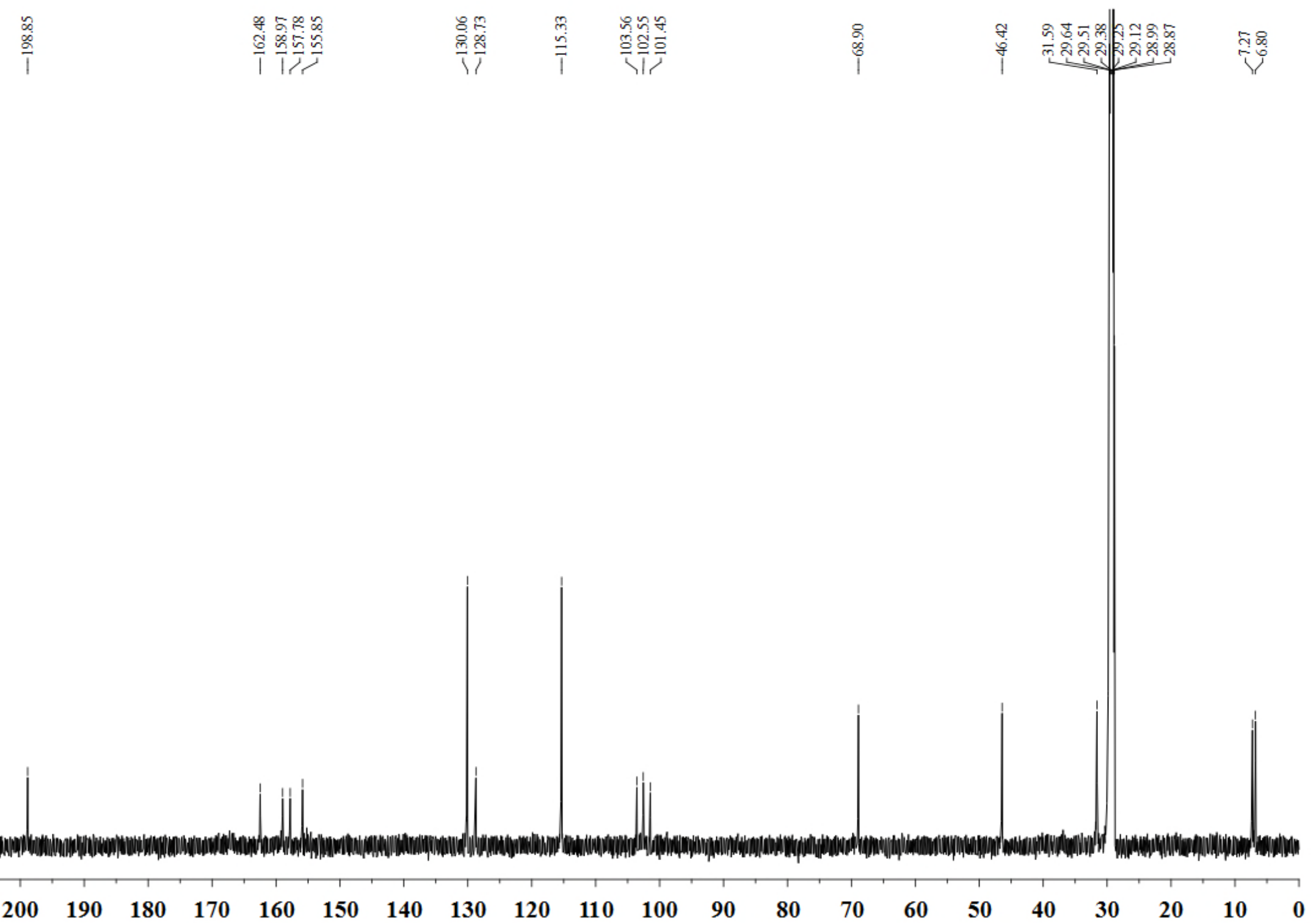

Figure S9 ${ }^{13} \mathrm{C}$ NMR of EA-3 (ppm, 600MHz, $\mathrm{CD}_{3} \mathrm{OD}$ ) 


\section{Peak EA-1:}

White yellow powder, $\mathrm{C}_{17} \mathrm{H}_{16} \mathrm{O}_{5}$, High Res. ESI-MS (40V): 299.0940 [M-H]', 193.0511 , 178.0282, 165.0555, 149.0612, 135.0087, 121.0296, 107.0498, 95.0141, 79.0190, 69.0346, 55.0193 (Figure S3A); ${ }^{1} \mathrm{H}-\mathrm{NMR}\left(600 \mathrm{MHz}, \mathrm{CD} 3 \mathrm{OH}\right.$, Figure S4): $1.92\left(3 \mathrm{H}, \mathrm{s}, 6-\mathrm{CH}_{3}\right), 2.79(1 \mathrm{H}, \mathrm{m}, \mathrm{H}-3)$, 2.65 (1H, dd, H-9a), 3.00 (1H, dd, H-9b), 4.10 (1H, dd, H-2a), 4.24 (1H, dd, H-2b), 6.01 (1H, s, H-8), $6.81\left(1 \mathrm{H}, \mathrm{d}, \mathrm{H}-3\right.$ ', 5'), 7.07 (1H, d, H-20,60), 12.35 (1 H, s, 5-OH). ${ }^{13} \mathrm{C} \mathrm{NMR}(600 \mathrm{MHz}, \mathrm{CD} 3 \mathrm{OH}$, Figure S5): $6.96\left(\mathrm{C}-6-\mathrm{CH}_{3}\right), 33.16$ (C-9), 47.56 (C-3), 69.83 (C-2), 95.13 (C-8), 102.33 (C-4a), 105.32 (C-6), 116.23 (C-3', 5'), 130.24 (C-2', 6'), 155.77 (C-4'), 161.54(C-5, 8a), 165.34 (C-7), 200.10 (C-4). EA-1 was assigned as 5, 7-dihydroxy-3-(4'-10 hydroxybenzyl)-6-methylchroman-4-one, which was a sappanin-type homoisoflavonoid.

\section{Peak EA-2:}

Pale yellow powder, $\mathrm{C}_{18} \mathrm{H}_{18} \mathrm{O}_{6}$, High Res. ESI-MS (40V): 329.1028 [M-H]', 208.0380, 193.0136, 180.0413, 165.0221, 152.0480, 137.0245, 124.0168, 109.0311, 96.0217, 79.0197 (Figure S3B). ${ }^{1} \mathrm{H}-\mathrm{NMR}\left(600 \mathrm{MHz}, \mathrm{CD} 3 \mathrm{OH}\right.$, Figure S6): $1.99\left(3 \mathrm{H}, \mathrm{s}, 6-\mathrm{CH}_{3}\right), 2.81(1 \mathrm{H}, \mathrm{m}, \mathrm{H}-3), 2.66(1 \mathrm{H}$, dd, H-9a), 3.11 (1H, dd, H-9b), 3.74 (3H, s, 8-OCH $), 4.14$ (1H, dd, H-2a), 4.30 (1H, dd, H-2b), 6.74 $\left(1 \mathrm{H}, \mathrm{d}, \mathrm{H}-3\right.$ ', 5') 7.05 (1H, d, H-2', 6'). 12.22 (1 H, s, 5-OH). ${ }^{13} \mathrm{C}$ NMR (600MHz, CD3OH, Figure S7): $7.24\left(\mathrm{C}-6-\mathrm{CH}_{3}\right), 33.23$ (C-9), 48.17 (C-3), 61.57 (C-8-CH$), 70.39$ (C-2), 102.38 (C-4a), 105.23 (C-6), 116.39 (C-3', 5'), 129.08 (C-8), 130.13 (C-1'), 131.14 (C-2', 6'), 152.92 (C-8a), 157.17 (C-4'), $158.60 \quad(\mathrm{C}-7), \quad 158.96 \quad(\mathrm{C}-5), \quad 199.60 \quad(\mathrm{C}-4) \quad \circ \quad \mathrm{EA}-2$ was assigned as (5,7-dihydroxy-3-(4'-hydroxybenzyl)-6-methyl-8-methoxychroman-4-one), which was a sappanin-type homoisoflavonoid.

\section{Peak EA-3:}

Pale yellow powder, $\mathrm{C}_{18} \mathrm{H}_{18} \mathrm{O}_{6}$, High Res. ESI-MS (40V): 313.1094 [M-1]', 298.6669, 207.0671, $192.0433,179.0791,163.0404,149.0257,135.0455,129.0570,123.0460$, 107.0512, 95.0156, 83.0521, 77.0409, 69.0363, 57.0362 (Figure S3C). ${ }^{1} \mathrm{H}$ NMR (600MHz, CD3OH, Figure S8): 1.94 $\left(3 \mathrm{H}, \mathrm{s}, 8-\mathrm{CH}_{3}\right), 2.06\left(3 \mathrm{H}, \mathrm{s}, 6-\mathrm{CH}_{3}\right), 2.61(1 \mathrm{H}, \mathrm{dd}, \mathrm{H}-9 \mathrm{a}), 2.83$ (1 H, m, H-3), 3.04 (1H, dd, H-9b), 4.09 (1H, dd, H-2a), 4.28 (1H, dd, H-2b), 6.75 (1H, d, H-3',5'), 7.04 (1H, d, H-2',6'). ${ }^{13} \mathrm{C}$ NMR (600MHz, CD3OH, Figure S9): $6.80\left(\mathrm{C}-8-\mathrm{CH}_{3}\right), 7.27\left(\mathrm{C}-6-\mathrm{CH}_{3}\right), 31.59(\mathrm{C}-9), 46.42(\mathrm{C}-3), 68.90$ (C-2), 101.45 (C-4a), 102.55 (C-8), 103.56 (C-6), 115.33 (C-3', 5'), 128.73 (C-1'), 130.06 (C-2', 6'), 155.85 (C-8a), 157.78 (C-4'), 158.97 (C-7), 162.48 (C-5), 198.85 (C-4). EA-3 was assigned as (5, 7-dihydroxy-3-(4'-hydroxybenzyl)-6, 8-dimethylchroman-4-one), which was a sappanin-type homoisoflavonoid. 